\title{
A model study of the impact of source gas changes on the stratosphere for 1850-2100
}

\author{
E. L. Fleming ${ }^{1,2}$, C. H. Jackman ${ }^{1}$, R. S. Stolarski ${ }^{1,3}$, and A. R. Douglass ${ }^{1}$ \\ ${ }^{1}$ NASA Goddard Space Flight Center, Greenbelt, MD, USA \\ ${ }^{2}$ Science Systems and Applications, Inc., Lanham, MD, USA \\ ${ }^{3}$ Department of Earth and Planetary Sciences, Johns Hopkins University, Baltimore, MD, USA
}

Received: 4 March 2011 - Published in Atmos. Chem. Phys. Discuss.: 12 April 2011

Revised: 3 August 2011 - Accepted: 6 August 2011 - Published: 22 August 2011

\begin{abstract}
The long-term stratospheric impacts due to emissions of $\mathrm{CO}_{2}, \mathrm{CH}_{4}, \mathrm{~N}_{2} \mathrm{O}$, and ozone depleting substances (ODSs) are investigated using an updated version of the Goddard two-dimensional (2-D) model. Perturbation simulations with the ODSs, $\mathrm{CO}_{2}, \mathrm{CH}_{4}$, and $\mathrm{N}_{2} \mathrm{O}$ varied individually are performed to isolate the relative roles of these gases in driving stratospheric changes over the 1850-2100 time period. We also show comparisons with observations and the Goddard Earth Observing System chemistry-climate model simulations for the time period 1960-2100 to illustrate that the 2-D model captures the basic processes responsible for longterm stratospheric change.

The ODSs, $\mathrm{CO}_{2}, \mathrm{CH}_{4}$, and $\mathrm{N}_{2} \mathrm{O}$ impact ozone via several mechanisms. ODS and $\mathrm{N}_{2} \mathrm{O}$ loading decrease stratospheric ozone via the increases in atmospheric halogen and odd nitrogen species, respectively. $\mathrm{CO}_{2}$ loading impacts ozone by: (1) cooling the stratosphere which increases ozone via the reduction in the ozone chemical loss rates, and (2) accelerating the Brewer-Dobson circulation (BDC) which redistributes ozone in the lower stratosphere. The net result of $\mathrm{CO}_{2}$ loading is an increase in global ozone in the total column and upper stratosphere. $\mathrm{CH}_{4}$ loading impacts ozone by: (1) increasing atmospheric $\mathrm{H}_{2} \mathrm{O}$ and the odd hydrogen species which decreases ozone via the enhanced $\mathrm{HOx}$-ozone loss rates; (2) increasing the $\mathrm{H}_{2} \mathrm{O}$ cooling of the middle atmosphere which reduces the ozone chemical loss rates, partially offsetting the enhanced HOx-ozone loss; (3) converting active to reservoir chlorine via the reaction $\mathrm{CH}_{4}+\mathrm{Cl} \rightarrow \mathrm{HCl}+\mathrm{CH}_{3}$ which leads to more ozone; and (4) increasing the $\mathrm{NO}_{\mathrm{x}}$-ozone production in the troposphere.
\end{abstract}

The net result of $\mathrm{CH}_{4}$ loading is an ozone decrease above $40-45 \mathrm{~km}$, and an increase below $40-45 \mathrm{~km}$ and in the total column.

The 2-D simulations indicate that prior to 1940, the ozone increases due to $\mathrm{CO}_{2}$ and $\mathrm{CH}_{4}$ loading outpace the ozone losses due to increasing $\mathrm{N}_{2} \mathrm{O}$ and carbon tetrachloride $\left(\mathrm{CCl}_{4}\right)$ emissions, so that total column and upper stratospheric global ozone reach broad maxima during the 1920s-1930s. This precedes the significant ozone depletion during $~ 1960$ 2050 driven by the ODS loading. During the latter half of the 21 st century as ODS emissions diminish, $\mathrm{CO}_{2}, \mathrm{~N}_{2} \mathrm{O}$, and $\mathrm{CH}_{4}$ loading will all have significant impacts on global total ozone based on the Intergovernmental Panel on Climate Change (IPCC) A1B (medium) scenario, with $\mathrm{CO}_{2}$ having the largest individual effect. Sensitivity tests illustrate that due to the strong chemical interaction between methane and chlorine, the $\mathrm{CH}_{4}$ impact on total ozone becomes significantly more positive with larger ODS loading. The model simulations also show that changes in stratospheric temperature, BDC, and age of air during 1850-2100 are controlled mainly by the $\mathrm{CO}_{2}$ and ODS loading. The simulated acceleration of the BDC causes the global average age of air above $22 \mathrm{~km}$ to decrease by $\sim 1 \mathrm{yr}$ from $1860-2100$. The photochemical lifetimes of $\mathrm{N}_{2} \mathrm{O}, \mathrm{CFCl}_{3}, \mathrm{CF}_{2} \mathrm{Cl}_{2}$, and $\mathrm{CCl}_{4}$ decrease by $11-13 \%$ during $1960-2100$ due to the acceleration of the BDC, with much smaller lifetime changes $(<4 \%)$ caused by changes in the photochemical loss rates.

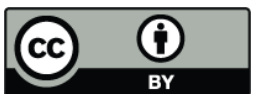

Correspondence to: E. L. Fleming

(eric.1.fleming@nasa.gov)

Published by Copernicus Publications on behalf of the European Geosciences Union. 


\section{Introduction}

Changes in the atmospheric abundance of halogenated ozone depleting substances (ODSs) and the greenhouse gases (GHGs) $\mathrm{CO}_{2}, \mathrm{CH}_{4}$, and $\mathrm{N}_{2} \mathrm{O}$ have been shown to significantly impact the chemical and dynamical structure of the stratosphere (e.g., World Meteorological Organization (WMO), 2007, 2011). For example, much of the decline of stratospheric ozone during the 1980s and 1990s has been attributed to increased atmospheric halogen loading due to anthropogenic forcings. Increases in $\mathrm{N}_{2} \mathrm{O}$ and the subsequent increase in odd nitrogen species decrease ozone in the middle stratosphere (e.g., Crutzen, 1976), while increases in $\mathrm{CO}_{2}$ and the subsequent cooling reduce the temperature dependent ozone loss rates and cause ozone increases in the upper stratosphere (e.g., Haigh and Pyle, 1979; Rosenfield et al., 2002).

Recent observational studies have detected the beginning of the ozone recovery process in the upper stratosphere, where ozone is most sensitive to changes in halogen loading (e.g., Reinsel, 2002; Newchurch et al., 2003). However, detection of the change in the halogen influence on ozone can be complicated by the impacts due to long-term changes in GHGs. It is therefore of interest to separate the relative impacts of the different chemical processes that control longterm ozone changes.

Another important aspect of the changing atmospheric composition impact on the stratosphere is the quantification of photochemical lifetimes of the ODSs and GHGs. These lifetimes have come under recent scrutiny (Douglass et al., 2008), as they are important for deriving surface mixing ratio boundary conditions from emissions estimates for use in atmospheric models (Kaye et al., 1994; WMO, 2011). The potential influence on lifetimes of the Brewer-Dobson circulation (BDC) acceleration due to climate change has also been investigated (Butchart and Scaife, 2001; Douglass et al., 2008).

Most studies of past and future stratospheric change now utilize three-dimensional (3-D) coupled chemistry-climate models (CCMs) (e.g., Eyring et al., 2006, 2007; WMO, 2011). Some 3-D CCM investigations have shown the impact of different processes on long-term stratospheric change, such as that due to the multi-decadal changes in ODS and GHG concentrations and sea surface temperatures (SSTs) (e.g., Butchart and Scaife, 2001; Austin et al., 2007; Olsen et al., 2007; Li et al., 2008; Eyring et al., 2010a, b; Austin et al., 2010). However, performing numerous sensitivity simulations to separate the different chemical processes that control stratospheric changes can be more easily done using twodimensional (2-D) models, given their much smaller computational requirements. 2-D models have been widely used in international assessments of the stratosphere (e.g., WMO, 2003, 2007, 2011), and past studies have shown that 2-D models can resolve much of the large scale stratospheric variability on monthly and longer time scales, as seen in com- parisons with observations and 3-D models (e.g., Plumb and Mahlman, 1987; Yudin et al., 2000; Fleming et al., 2007; Newman et al., 2009). Previous 2-D model studies have investigated the relative roles of the long-term changes in $\mathrm{CO}_{2}$, $\mathrm{CH}_{4}$, and $\mathrm{N}_{2} \mathrm{O}$, focussing on the stratospheric ozone changes over the next century (e.g., Randeniya et al., 2002; Chipperfield and Feng, 2003; Portmann and Solomon, 2007).

In this paper we expand on these previous studies and examine in more detail the relative contributions of the longterm changes in atmospheric GHG and ODS loading using our recently upgraded Goddard Space Flight Center (GSFC) 2-D coupled chemistry-radiation-dynamics model. We exploit the computational speed of the 2-D model to perform numerous perturbation simulations to investigate the stratospheric impacts due to GHG and ODS loading for the 250-yr time period, 1850-2100. We examine the ozone, temperature, and age of air impacts, and focus on the time periods prior to 1950 and the latter half of the 21 st century. We also use perturbation tests to examine the ozone impacts due to the chemical coupling between $\mathrm{CH}_{4}$ and chlorine. We then investigate the long-term time dependence of the photochemical lifetimes of $\mathrm{N}_{2} \mathrm{O}, \mathrm{CFC}-11, \mathrm{CFC}-12$, and $\mathrm{CCl}_{4}$. Here, we examine the relative importance of changes in the BDC and the photochemical loss rates in controlling these lifetimes.

The recent Stratospheric Processes and Their Role in Climate (SPARC) Chemistry-Climate Model Validation Activity (SPARC CCMVal, 2010) provided a comprehensive process oriented evaluation of many CCMs. Because 2-D models were not included in this activity, and given the recent improvements to our 2-D model, we provide in Appendices $\mathrm{A}$ and $\mathrm{B}$, a detailed description and evaluation of our upgraded model, comparing climatological simulations with observations of various stratospheric tracers. Throughout the paper, we also compare long term simulations from the 2-D model with the Goddard Earth Observing System chemistryclimate model (GEOSCCM) and multi-decadal observational data sets to illustrate that the 2-D model captures the basic processes that drive long-term changes in stratospheric ozone, temperature, and age of air. The good 2-D model agreement with the measurements and the GEOSCCM then justifies the use of the 2-D model for the perturbations addressed in this study.

\section{Model simulations}

For this study, we utilize a series of 2-D model experiments in which the surface concentrations of only the ODSs or the individual GHGs are varied time dependently for 18502100, while all other source gases are fixed at low (1850) levels. In this way, we separate the individual effects of the ODS and GHG loading. We compare these with the 2$\mathrm{D}$ baseline simulation in which all source gases are varied time dependently, and with the GEOSCCM baseline simulation for 1950-2100. The GEOSCCM couples the GEOS-4 general circulation model with stratospheric chemistry and 


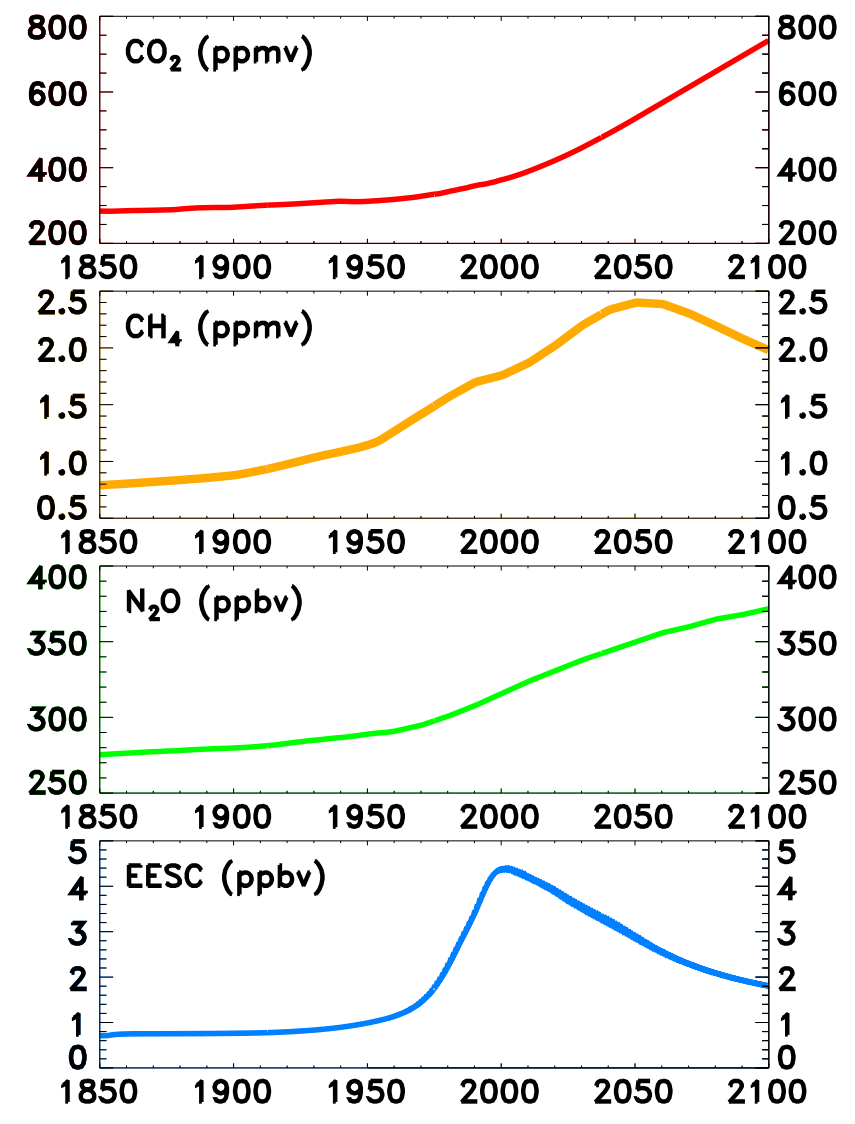

Fig. 1. Time dependent surface boundary conditions for $\mathrm{CO}_{2}$ (top), $\mathrm{CH}_{4}$ (middle top), and $\mathrm{N}_{2} \mathrm{O}$ (middle bottom) from Hansen and Sato (2004) for 1850-1950 and the IPCC GHG scenario A1B for 1950-2100. The bottom panel shows the upper stratospheric Equivalent Effective Stratospheric Chlorine (EESC) taken as the global average of $\mathrm{Cl}_{\mathrm{y}}+60 \mathrm{Br}_{\mathrm{y}}$ at $50 \mathrm{~km}$. See text for details.

has been applied to various stratospheric problems (e.g., Stolarski et al., 2006; Pawson et al., 2008; Waugh et al., 2009; Oman et al., 2009; Newman et al., 2009; Li et al., 2009). The GEOSCCM uses specified time dependent SSTs and sea-ice amounts, and the results presented in this study are comprised of three simulations which utilize somewhat different SSTs for the past and future time periods: 1950-2004, 19712052, and 1996-2100.

For 1950-2100, the 2-D and GEOSCCM simulations use surface ODS boundary conditions from scenario A1 of WMO (2007), and GHG boundary conditions from scenario A1B (medium) from the Intergovernmental Panel on Climate Change (IPCC) Special Report on Emissions Scenarios (IPCC, 2000). The 2-D simulations for 1850-1950 use GHG surface boundary conditions from Hansen and Sato (2004). For the ODSs, most are zero prior to 1950, except for the following: $\mathrm{CFCl}_{3}$ and $\mathrm{CF}_{2} \mathrm{Cl}_{2}$ are set to zero prior to 1935 and 1946, respectively, and are then ramped up slowly to the 1950 WMO (2007) values. $\mathrm{CCl}_{4}$ is ramped up exponentially from

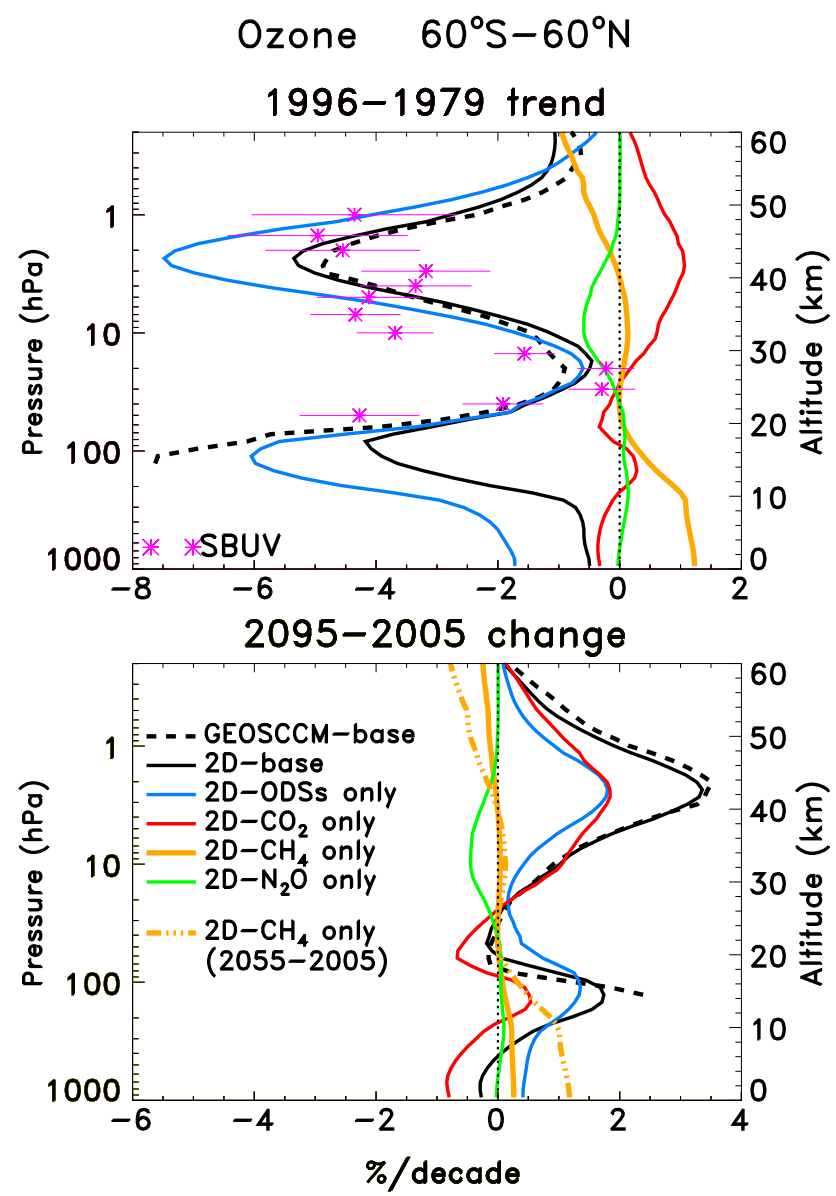

Fig. 2. (Top) Vertical profiles of the annual and near-global average $\left(60^{\circ} \mathrm{S}-60^{\circ} \mathrm{N}\right)$ ozone trend $\left(\%\right.$ decade $\left.^{-1}\right)$ for $1996-1979$ derived from the SBUV data and model simulations. Shown are the base simulations (all source gases varied time dependently) of the GEOSCCM (black dashed lines) and 2-D model (black solid lines), along with 2-D simulations in which only certain source gases are varied as follows: ODSs only (blue lines); $\mathrm{CO}_{2}$ only (red lines); $\mathrm{CH}_{4}$ only (orange lines); $\mathrm{N}_{2} \mathrm{O}$ only (green lines). The trends are derived from regression fits to the EESC time series (Fig. 1) for 1979-2004. (Bottom) As in the top but for the 2095-2005 ozone difference $\left(\%\right.$ decade $^{-1}$ ) using 10-yr averages centered on 2095 and 2005 to reduce the effects of interannual dynamical variability in the GEOSCCM. The change due to $\mathrm{CH}_{4}$ is shown for 2095-2005 (orange solid) and 2055-2005 (orange dashed-dotted).

zero in 1900 to the 1950 value of WMO (2007), approximating the time series of Butler et al. (1999). $\mathrm{CH}_{3} \mathrm{Cl}$ and $\mathrm{CH}_{3} \mathrm{Br}$ are set to 440 parts per trillion by volume (pptv) and 5 pptv, respectively in 1850, and follow the time variation up to 1950 as discussed in Butler et al. (1999) and WMO (2003). The corresponding GHG surface boundary conditions for 18502100 are shown in Fig. 1, along with the Equivalent Effective Stratospheric Chlorine (EESC, bottom panel) representing the time dependent concentration of total chlorine (Cly) and total bromine (Bry) loading from the ODS source gases. 
Ozone trend (\%/decade) 1996-1979
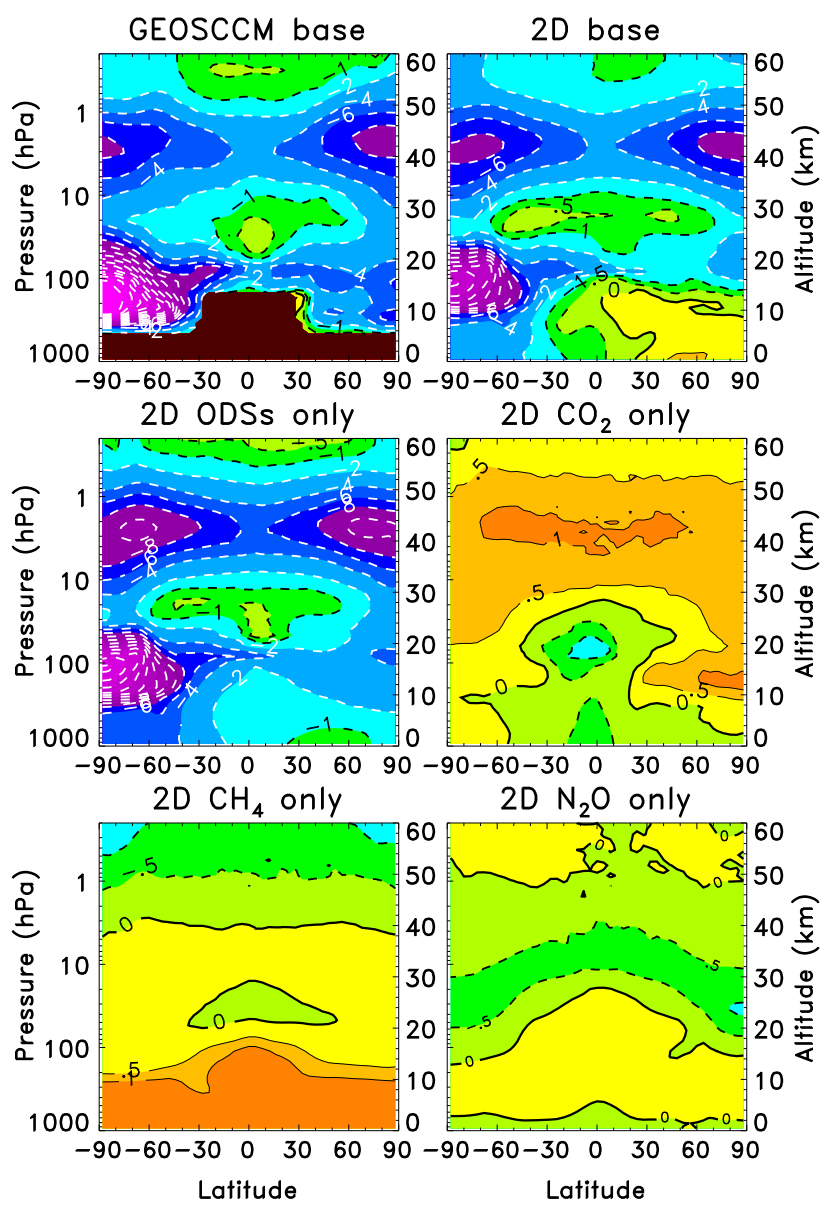

Fig. 3. Annually averaged ozone trend for 1996-1979 derived from the GEOSCCM and 2-D model simulations. The top panels are from the base simulations in which all source gases are varied time dependently. The middle and bottom panels show 2-D simulations in which only the ODSs or GHGs are varied time dependently as indicated. The trends are derived from regression fits to the EESC time series (Fig. 1) for 1979-2004. The GEOSCCM trends are not computed in the troposphere as ozone is relaxed to a climatology in this region. The contour intervals are $\pm 2 \%$ decade $^{-1}$ and include the \pm 5 and $\pm 1 \%$ decade $^{-1}$ contours. The purple and blue colors indicate the largest negative values, and the orange and yellow colors indicate the largest positive values.

Here, EESC is taken as the global average of $\mathrm{Cl}_{\mathrm{y}}+60 \mathrm{Br}_{\mathrm{y}}$ at $50 \mathrm{~km}$. Note that all 2-D and GEOSCCM calculations use fixed solar flux (no solar cycle variations) and clean stratospheric aerosol conditions specified from WMO (2007).
Ozone change (\%/decade) 2095-2005
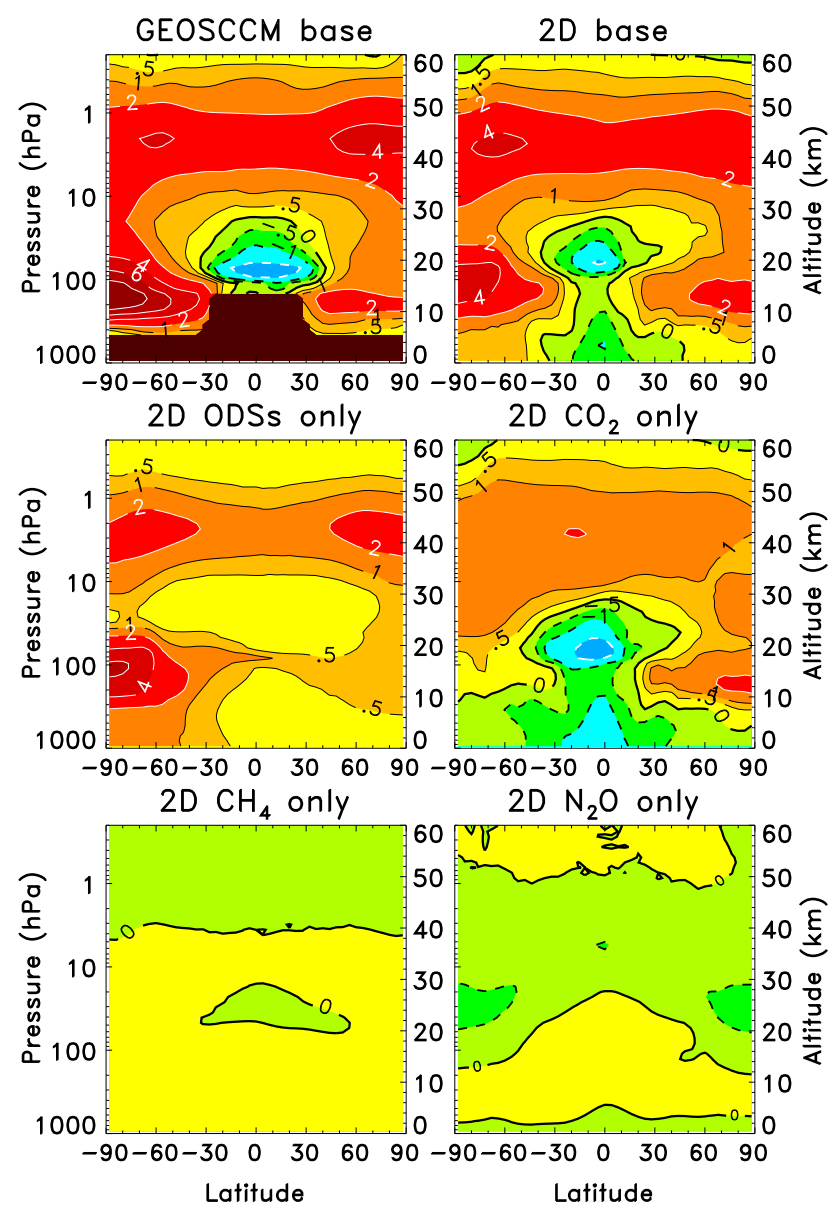

Fig. 4. As in Fig. 3, except for the 2095-2005 ozone difference using 10-yr averages centered on 2095 and 2005 to reduce the effects of interannual dynamical variability in the GEOSCCM. The contour intervals are $\pm 2 \%$ decade $^{-1}$ and include the \pm 5 and $\pm 1 \%$ decade $^{-1}$ contours.

\section{Ozone}

\subsection{Base model-data comparisons}

As a general model evaluation, we first compare the simulated vertical profile ozone trends for 1979-1996 with the Solar Backscatter UltraViolet (SBUV) data for the near-global $\left(60^{\circ} \mathrm{S}-60^{\circ} \mathrm{N}\right)$ average (Fig. 2, top). These are derived from regression fits to the EESC time series (Fig. 1) for 19792004. At $50 \mathrm{hPa}$ (the lowest level of the SBUV data), the observationally-derived trend is underestimated in the 2-D base simulation (all source gases varied time dependently), less so in the GEOSCCM. However above $20 \mathrm{~km}$, both base simulations are mostly in reasonable agreement with the observations. Note that we do not show GEOSCCM results in the troposphere as ozone is relaxed to an observational climatology in this region. 
The recent past and future ozone changes in the 2-D model are also mostly similar to the GEOSCCM in the near global average (Fig. 2) and in the latitude-height variations (Figs. 3 and 4). This general model agreement is also seen in time series of near-global profile ozone (Fig. 5), global total ozone (Fig. 6), and tropical total ozone (Fig. 7). For reference, we include time series of the BUV/SBUV satellite observations for profile ozone and ground-base data for global total ozone (updated from Fioletov et al., 2002).

The largest 2-D-GEOSCCM differences occur in the Antarctic ozone hole region, where the 2-D model simulates smaller past (negative) and future (positive) ozone changes compared to the GEOSCCM (Figs. 3 and 4). Some of this is likely due to the 2-D model not fully resolving the processes that control polar ozone loss, as these can have large zonal asymmetries. Some of this model difference also reflects the known high ozone bias in the high latitude lower stratosphere in the GEOSCCM. This bias is most pronounced during periods of low chlorine loading so that the chlorineinduced changes in the Antarctic spring are too large by 60 $80 \%$ (Pawson et al., 2008). These model differences are reflected in the near-global averaged vertical profiles below $18 \mathrm{~km}$ (Fig. 2) and in the total column time series (Fig. 6) in which the GEOSCCM simulates significantly more past ozone reduction and future ozone increase. However, the generally good agreement between the 2-D model base simulations and the observations and GEOSCCM in Figs. 2-7 show that the 2-D model captures the basic processes responsible for long-term stratospheric ozone changes.

\subsection{2-D perturbation simulations}

The relative roles of ODS, $\mathrm{CO}_{2}, \mathrm{CH}_{4}$, and $\mathrm{N}_{2} \mathrm{O}$ loading in controlling the recent past and future ozone changes are illustrated by the 2-D model perturbation simulations in Figs. 27. This includes the well known dominance of ODS loading in controlling the sharp ozone decline in the lower and upper stratosphere globally during $\sim 1970-2000$. ODS loading also largely controls the tropical total ozone time series from $\sim 1970$ through the early 21 st century (Fig. 7), due to the strong ODS impact in the upper stratosphere (Figs. 3 and 4).

$\mathrm{CO}_{2}$ cooling and subsequent reduction in the ozone loss rates produce a broad ozone increase of $1-2 \%$ decade $^{-1}$ in the upper stratosphere (Figs. 2-4). For the 2005-2095 time period, the ozone increases due to increasing $\mathrm{CO}_{2}$ and declining ODS emissions are similar in the upper stratosphere (1.5$2 \%$ decade $^{-1}$ ) in Fig. 2 (bottom) and Fig. 4. By 2100, $\mathrm{CO}_{2}$ loading is the dominant impact at $40 \mathrm{~km}$, causing a $20 \%$ increase in ozone from 1850-2100 (Fig. 5, middle, red curve).

Previous CCM studies have shown that increased GHG loading results in an acceleration of the BDC with related impacts on ozone and trace gases (e.g., Butchart and Scaife, 2001; Austin and Li, 2006; Garcia and Randel, 2008; Li et al., 2009). This feature is seen in the 2-D CO 2 -only simulation in Figs. 3 and 4, in which lower tropical stratospheric

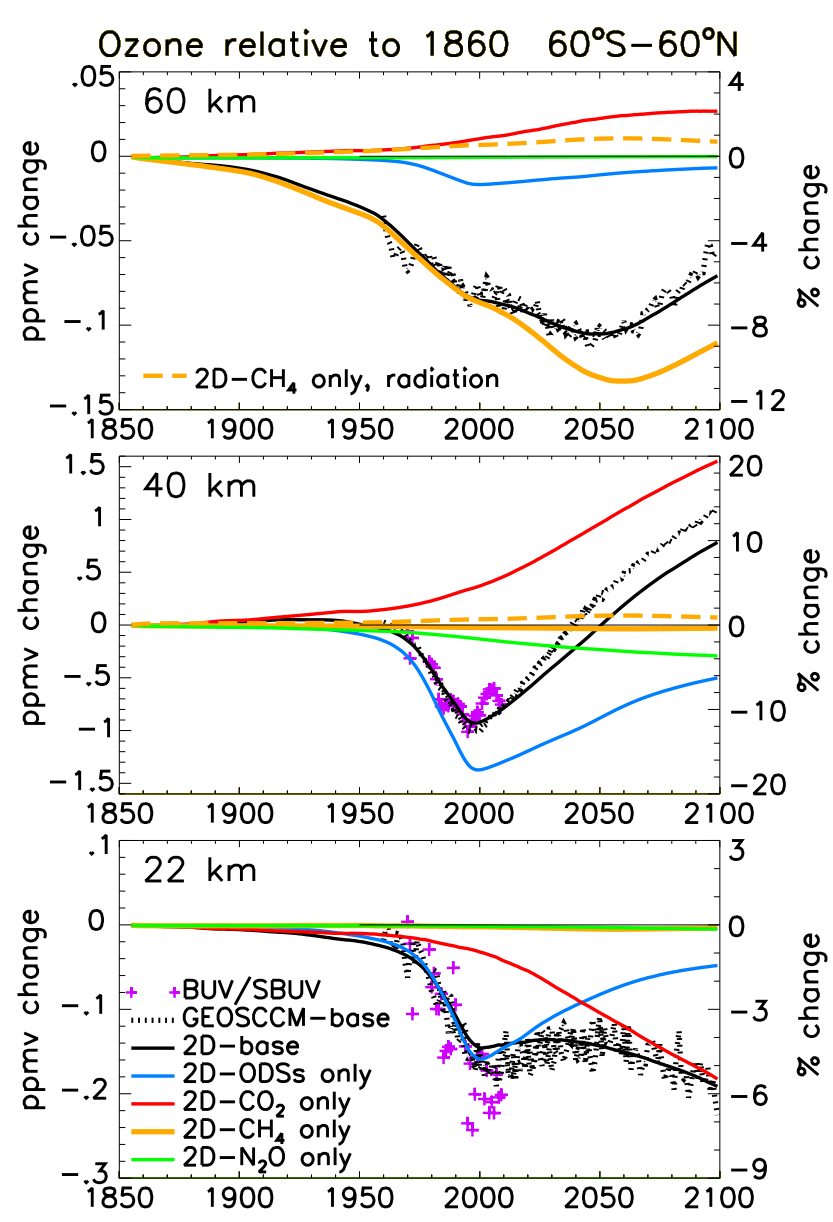

Fig. 5. Near global $\left(60^{\circ} \mathrm{S}-60^{\circ} \mathrm{N}\right)$ annually averaged ozone time series for $1860-2100$, relative to 1860 , at 22,40 , and $60 \mathrm{~km}$. Values are in ppmv change (left axes) and \% change (right axes). Shown are the base simulations (all source gases varied time dependently) of the GEOSCCM (black dotted lines) and 2-D model (black solid lines), along with 2-D simulations in which only certain source gases are varied as follows: ODSs only (blue solid); $\mathrm{CO}_{2}$ only (red solid); $\mathrm{CH}_{4}$ only (orange solid); and $\mathrm{N}_{2} \mathrm{O}$ only (green solid) (the other source gases are fixed at 1850 levels in these simulations). Also shown is a 2-D simulation in which only the radiative impacts of $\mathrm{CH}_{4}$ are included (orange dashed). The GEOSCCM time series has been adjusted to match the 2-D base simulation for 1960 . Also shown are the BUV/SBUV satellite observations for 19702009 (excluding 1973-1978) at 22 and $40 \mathrm{~km}$ ("+" symbols). To emphasize the model-data comparison after 1970, the data have been adjusted so that the 1970-1972 average matches that of the base simulations.

ozone is reduced by $1-2 \%$ decade $^{-1}$ as ozone-poor air is advected upwards from the tropical troposphere. There is a compensating downward advection of ozone-rich air in the extratropics at $10-15 \mathrm{~km}$ which is strongest in the Northern Hemisphere (NH). This hemispheric asymmetry is consistent with previous GEOSCCM simulations of the climate change impacts on ozone (Olsen et al., 2007; Li et al., 2009; Waugh 


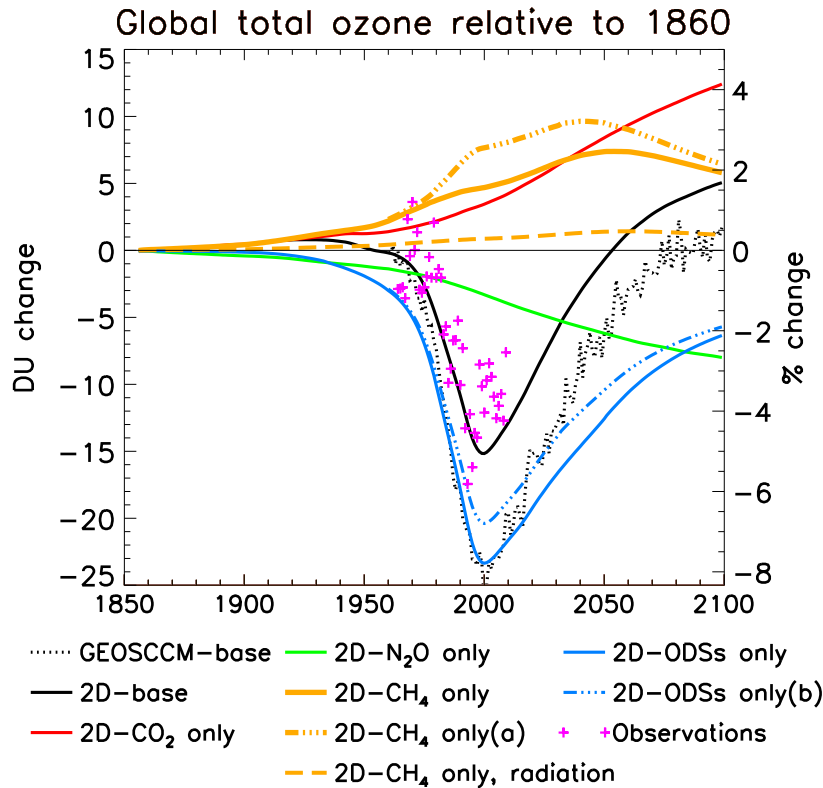

Fig. 6. Global and annual averaged total ozone time series relative to 1860 values. Shown are the base simulation (all source gases varied time dependently) from the 2-D model (black solid line) and GEOSCCM (black dotted line). The GEOSCCM time series has been adjusted to match the 2-D base simulation for 1960 . Also shown are 2-D simulations in which only certain source gases are varied time dependently as follows: $\mathrm{CO}_{2}$ only (red solid); $\mathrm{N}_{2} \mathrm{O}$ only (green solid); $\mathrm{CH}_{4}$ only (orange solid); and ODSs only (blue solid), with the other source gases fixed at 1850 levels. The "+" symbols represent ground-based data updated from Fioletov et al. (2002). To emphasize the model-data comparison after 1970, the data have been adjusted so that the 1964-1970 average matches that of the base simulations. Also shown are the combined effects of $\mathrm{CH}_{4}$ and ODSs loading: the 2-D- $\mathrm{CH}_{4}$ only(a) curve (orange dashed-dotted) is the difference between a simulation with $\mathrm{CH}_{4}$ and the ODSs varied time dependently and that with only the ODSs varied time dependently, showing the effect of $\mathrm{CH}_{4}$ in the presence of time dependent ODS loading; the 2-D-ODSs only(b) curve (blue dasheddotted) is the difference between a simulation with $\mathrm{CH}_{4}$ and the ODSs varied time dependently and that with only $\mathrm{CH}_{4}$ varied time dependently, showing the effect of ODSs in the presence of time dependent $\mathrm{CH}_{4}\left(\mathrm{CO}_{2}\right.$ and $\mathrm{N}_{2} \mathrm{O}$ are fixed at 1850 levels in these simulations). The orange dashed curve depicts a simulation in which only the radiative impacts of $\mathrm{CH}_{4}$ loading are included. Values are in Dobson Unit (DU) change (left axes) and \% change (right axes).

et al., 2009). These BDC-driven ozone changes are reflected in the global average in Fig. 2, with an ozone decrease (increase) of $\sim 0.5 \%$ decade $^{-1}$ centered near $20 \mathrm{~km}(15 \mathrm{~km})$ in the 2-D $\mathrm{CO}_{2}$-only simulation. The $\mathrm{CO}_{2}$-induced ozone decrease is dominant by 2100 in the near global average time series at $22 \mathrm{~km}$ (Fig. 5, bottom, red curve), with a decrease of $5.5 \%$ from 1850-2100. At this level, $\mathrm{N}_{2} \mathrm{O}$ and $\mathrm{CH}_{4}$ loading have negligible impacts, so that the net result of ODS and $\mathrm{CO}_{2}$ changes is an ozone increase from 2000-2030 and a decrease from 2030-2100 in the base simulations.

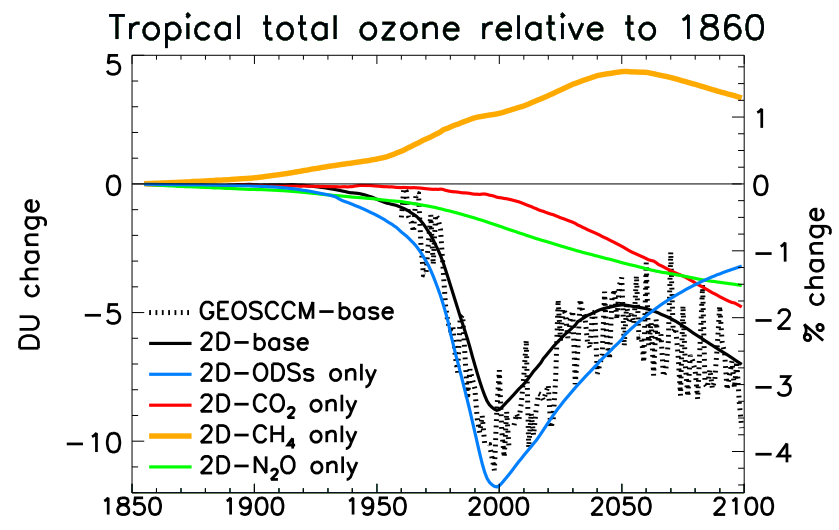

Fig. 7. Annual averaged tropical $\left(10^{\circ} \mathrm{S}-10^{\circ} \mathrm{N}\right.$ average $)$ total ozone time series relative to 1860 values. Shown are the base simulation (all source gases varied time dependently) from the 2D model (black solid line) and GEOSCCM (black dotted line). The GEOSCCM time series has been adjusted to match the 2D base simulation for 1960. Also shown are 2-D simulations in which only certain source gases are varied time dependently as follows: ODSs only (blue solid); $\mathrm{CO}_{2}$ only (red solid); $\mathrm{CH}_{4}$ only (orange solid); and $\mathrm{N}_{2} \mathrm{O}$ only (green solid), with the other source gases fixed at 1850 levels. For visual clarity, the observations are not shown as these are dominated by the large quasi-biennial oscillation, a feature not included in the simulations. Values are in Dobson Unit (DU) change (left axes) and \% change (right axes).

The net impact of $\mathrm{CO}_{2}$ loading on total ozone is an increase of 12.5 Dobson Units (DU) (4.2\%) from 1850-2100 in the global average (Fig. 6, red curve). $\mathrm{CO}_{2}$ loading also increases total ozone at midlatitudes of both hemispheres (not shown), and as with profile ozone, the total column increase is more pronounced in the NH compared to the Southern Hemisphere ( $\mathrm{SH}$ ) midlatitudes owing to the larger enhancement of the BDC north of the equator. In the tropics, the enhancement of the BDC advecting ozone-poor air from the troposphere counteracts the ozone increase in the upper stratosphere caused by the $\mathrm{CO}_{2}$ cooling. The net effect is a decrease in tropical total column ozone throughout the $21 \mathrm{st}$ century in Fig. 7 (red curve), consistent with previous CCM results (Li et al., 2009; Waugh et al., 2009; Eyring et al., 2010b).

In Figs. 2-5, $\mathrm{N}_{2} \mathrm{O}$ loading and the subsequent increase in stratospheric $\mathrm{NO}_{\mathrm{y}}$ lead to a decrease in stratospheric ozone, with a maximum decline of $0.5-0.6 \%$ decade $^{-1}$ near $35 \mathrm{~km}$ in the global average in both the past and future. These magnitudes are slightly less than obtained by Portmann and Solomon (2007) who used the IPCC A2 GHG scenario which has larger $\mathrm{N}_{2} \mathrm{O}$ increases compared to the A1B scenario used here. From $1850-2100, \mathrm{~N}_{2} \mathrm{O}$ loading results in a total ozone decrease of $8 \mathrm{DU}(-2.7 \%)$ in the global average (Fig. 6) and $4 \mathrm{DU}(-1.5 \%)$ in the tropics (Fig. 7). This effect of $\mathrm{N}_{2} \mathrm{O}$ loading taken in isolation is larger than would be when taking into account the effects of increased $\mathrm{CO}_{2}$ cooling on future 


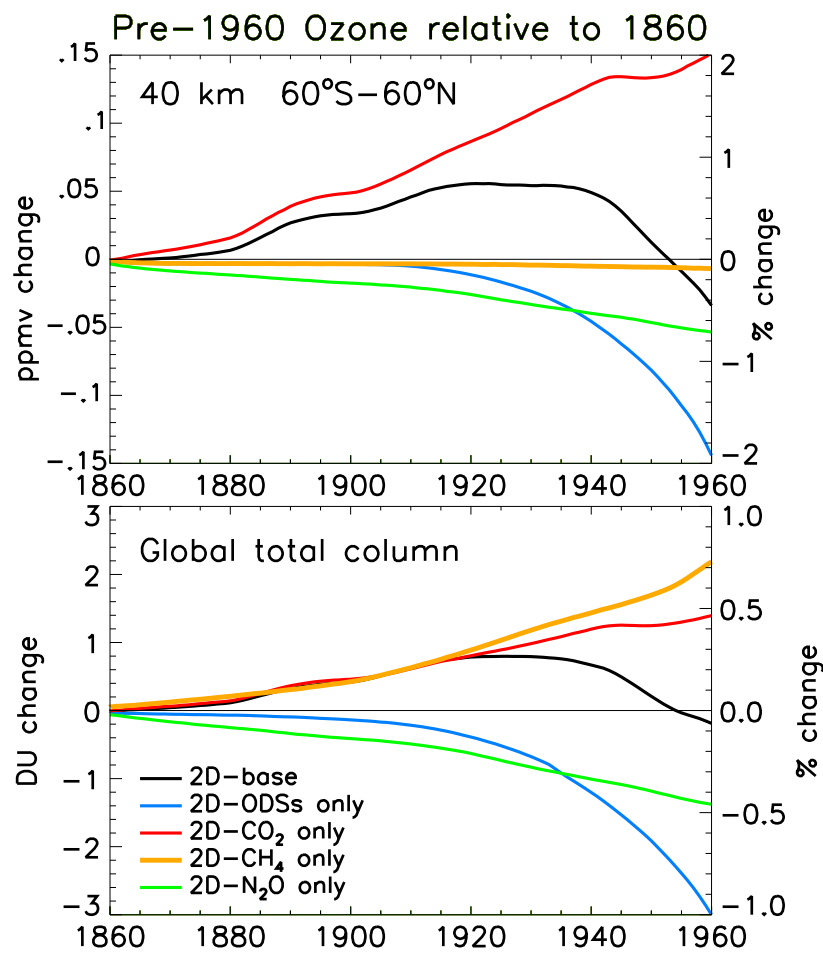

Fig. 8. Ozone time series for $1860-1960$, relative to 1860 values, from 2-D model simulations for the $60^{\circ} \mathrm{S}-60^{\circ} \mathrm{N}$ average at $40 \mathrm{~km}$ (top), and the $90^{\circ} \mathrm{S}-90^{\circ} \mathrm{N}$ average total column (bottom). Shown are the base simulation (all source gases varied time dependently, black solid) and simulations in which only certain source gases are varied time dependently as follows: ODSs only (blue solid); $\mathrm{CO}_{2}$ only (red solid); $\mathrm{CH}_{4}$ only (orange solid); and $\mathrm{N}_{2} \mathrm{O}$ only (green solid), with the other source gases fixed at 1850 levels. Values are in Dobson Unit (DU) change (left axes) and \% change (right axes).

$\mathrm{NO}_{\mathrm{y}}$ and ozone changes, as has been discussed previously (Rosenfield and Douglass, 1998; Daniel et al., 2010). We will discuss this in more detail in Sect. 3.5.

Atmospheric $\mathrm{CH}_{4}$ impacts ozone via several mechanisms: (1) $\mathrm{CH}_{4}$ loading increases the amount of $\mathrm{H}_{2} \mathrm{O}$ in the stratosphere and mesosphere which in turn reduces ozone by enhancing the $\mathrm{HO}_{\mathrm{x}}$-ozone loss cycles; (2) these $\mathrm{H}_{2} \mathrm{O}$ increases also cool the middle atmosphere, thereby increasing ozone by reducing the ozone loss rates; (3) increases in $\mathrm{CH}_{4}$ lead to increased ozone throughout the stratosphere by converting active chlorine to the reservoir $\mathrm{HCl}$ via the reaction $\mathrm{CH}_{4}+\mathrm{Cl} \rightarrow \mathrm{HCl}+\mathrm{CH}_{3}$; and (4) increases in $\mathrm{CH}_{4}$ lead to increased ozone in the troposphere and very lower stratosphere due $\mathrm{NO}_{\mathrm{x}}$-induced ozone production (e.g., Brasseur and Solomon, 1986). This latter mechanism is strongly dependent on the amount of tropospheric $\mathrm{NO}_{\mathrm{x}}$. To more properly account for this in the 2-D model, we constrain the model troposphere using output from the Global Modeling Initiative's (GMI) combined stratosphere-troposphere chemistry and transport model (GMI Combo CTM) (Strahan et al., 2007; Duncan et al., 2007). This includes specifying the boundary conditions for the odd nitrogen species below $5 \mathrm{~km}$, and the $\mathrm{NO}_{\mathrm{x}}$ lightning production and $\mathrm{HNO}_{3}$ washout throughout the troposphere, all for present day conditions. The resulting 2-D tropospheric $\mathrm{NO}_{\mathrm{x}}$ and $\mathrm{NO}_{\mathrm{y}}$ distributions compare favorably with the GMI model. The 2-D model utilized in this way simulates a mid-upper tropospheric ozone response to a steady state $\mathrm{CH}_{4}$ perturbation $(0.5$ parts per million by volume, ppmv) similar to that obtained in the GMI model for present day conditions.

Figures 2-5 show that the combined effect of the $\mathrm{CH}_{4}$ mechanisms outlined above yield a significant ozone increase $\left(1-1.5 \% \mathrm{decade}^{-1}\right)$ in the troposphere and very lower stratosphere, a mostly weak positive response at $20-40 \mathrm{~km}$, and a negative ozone response above $40 \mathrm{~km}$ with decreases of $1 \%$ decade $^{-1}$ and larger above $60 \mathrm{~km}$. Figure 5 (top panel) shows that $\mathrm{CH}_{4}$ loading is dominant in controlling the ozone time dependence at $60 \mathrm{~km}$, due to the subsequent increase in $\mathrm{H}_{2} \mathrm{O}$ and $\mathrm{HO}_{\mathrm{x}}$-ozone loss. This mechanism also results in significant $\mathrm{CH}_{4}$-induced ozone loss at $60 \mathrm{~km}$ prior to 1960 so that one-third of the total decrease in ozone during 18502050 has occurred by 1960 . For total ozone, $\mathrm{CH}_{4}$ loading results in increases from $1850-2050$ of $7.5 \mathrm{DU}(2.5 \%)$ in the global average (Fig. 6) and 4.5 DU (1.7\%) in the tropics (Fig. 7).

To isolate the $\mathrm{H}_{2} \mathrm{O}$ cooling impact due to methane loading, we ran an additional simulation in which only this radiative process was included. This simulation revealed a cooling of $\sim 0.7 \mathrm{~K}$ globally at $30-60 \mathrm{~km}$ from $1850-2050$, resulting in an ozone increase of $1-1.5 \%$ at $40-60 \mathrm{~km}$ and a total column increase of 1.5 DU during this time period (Figs. 5-6, orange-dashed curves). While this effect is small it is not insignificant, contributing about $20 \%$ of the total $\mathrm{CH}_{4}$-induced increase in total ozone from 1850-2050 (1.5 out of 7.5 DU).

The future ozone response to $\mathrm{CH}_{4}$ follows the surface boundary condition, which is significantly larger in 2055 than in 2100 in the A1B scenario (Fig. 1). This results in a relatively small change from 2005-2095 seen in the latitude-height section in Fig. $4\left(< \pm 0.5 \%\right.$ decade $^{-1}$ everywhere). We show vertical profile results for both 2005-2055 and 2005-2095 in Fig. 2, illustrating the much different magnitudes of the response for the different time periods. These responses are also qualitatively similar but have smaller magnitudes compared to Portmann and Solomon (2007) who used IPCC scenario A2 which has larger GHG loading. We note that because the 2-D model tropospheric $\mathrm{NO}_{\mathrm{x}}$ and $\mathrm{NO}_{\mathrm{y}}$ are fixed to the present day GMI simulation, the tropospheric ozone response to the time dependent $\mathrm{CH}_{4}$ perturbation shown in Figs. 2-7 does not account for long-term changes in tropospheric $\mathrm{NO}_{\mathrm{x}}$ emissions. These have undergone significant past increases which would lead to more $\mathrm{CH}_{4}$-induced tropospheric ozone production than we show in Figs. 2-7.

By 2100 , ODS, $\mathrm{CO}_{2}, \mathrm{CH}_{4}$, and $\mathrm{N}_{2} \mathrm{O}$ loading all play important roles in controlling global total ozone. $\mathrm{CO}_{2}$ has the largest impact, leading to a $4 \%$ increase from 1860-2100, 
with $\mathrm{CH}_{4}$ loading causing a $2 \%$ increase, and $\mathrm{N}_{2} \mathrm{O}$ and ODS loading each contributing a $2-2.5 \%$ decrease from 1860 2100 (Fig. 6). The net result is a $1.7 \%$ (5 DU) increase from 1860-2100 in the 2-D base simulation. In the tropics, baseline total ozone increases during 2000-2050. This is followed by a $\sim 1 \%$ decrease over the second half of the century, as the combination of increasing $\mathrm{CO}_{2}$ and $\mathrm{N}_{2} \mathrm{O}$ and decreasing $\mathrm{CH}_{4}$ more than offset the effect of reduced ODS loading. This general time variation of 21 st century tropical total ozone is consistent with the GEOSCCM in Fig. 7 and other CCM results reported recently (Eyring et al., 2010a, b; Austin et al., 2010).

\subsection{0-1960 ozone}

As seen in Figs. 5-7, the ozone changes prior to 1960 are relatively small, but not insignificant, compared to post-1960. To examine these more closely, Fig. 8 shows a close-up of the 1860-1960 ozone time series for the near-global average at $40 \mathrm{~km}$ and the global average total column.

From 1860-1960, the total column impacts due to $\mathrm{CO}_{2}$ and $\mathrm{N}_{2} \mathrm{O}$ are approximately equal and opposite, being $+0.5 \%$ and $-0.5 \%$, respectively. The $\mathrm{CH}_{4}$ impact is slightly larger by $1960(+0.75 \%)$. The ODS impact, which is due mainly to $\mathrm{CCl}_{4}$ emissions, causes a $1 \%$ depletion in the total column by 1960 , with the vast majority of this decrease occuring after 1920 . At $40 \mathrm{~km}$, the impact of $\mathrm{CO}_{2}$ cooling leads to a $2 \%$ ozone increase from 1860-1960, which is approximately equal and opposite to the ozone depletion caused by ODSs.

Ozone in the resulting base simulation (black curves) reaches broad pre-modern maxima during 1920-1940, with increases from 1860 of $0.8 \mathrm{DU}(0.3 \%)$ in the total column and $0.06 \mathrm{ppmv}(0.8 \%)$ at $40 \mathrm{~km}$. This preceeds the decline in ozone driven mainly by ODS loading, which becomes much more rapid after $\sim 1970$ (Figs. 5 and 6).

\section{4 $\mathrm{CH}_{4}$ sensitivity experiments}

Since the changes in $\mathrm{CH}_{4}$ impact ozone via different chemical mechanisms as outlined above, we now examine these chemical effects in more detail (the radiative impacts of $\mathrm{CH}_{4}$ are fixed in these experiments). Figure 9 (top panel) shows the global/annual averaged 2-D model steady state ozone change due to a $0.5 \mathrm{ppmv} \mathrm{CH}_{4}$ perturbation for year 2000 conditions. This is expressed in DU km${ }^{-1}$ to emphasize the contribution to the total column change. $\mathrm{CH}_{4}$ is lost via reaction with $\mathrm{O}\left({ }^{1} \mathrm{D}\right), \mathrm{OH}$, and $\mathrm{Cl}$, and the black curve shows the standard case in which all three reactions use the perturbed $\mathrm{CH}_{4}$. This shows that the $\mathrm{CH}_{4}$ impact on ozone is positive everywhere below $46 \mathrm{~km}$, with only a very small negative change above $46 \mathrm{~km}$, and a total column response of $+2.7 \mathrm{DU}$.

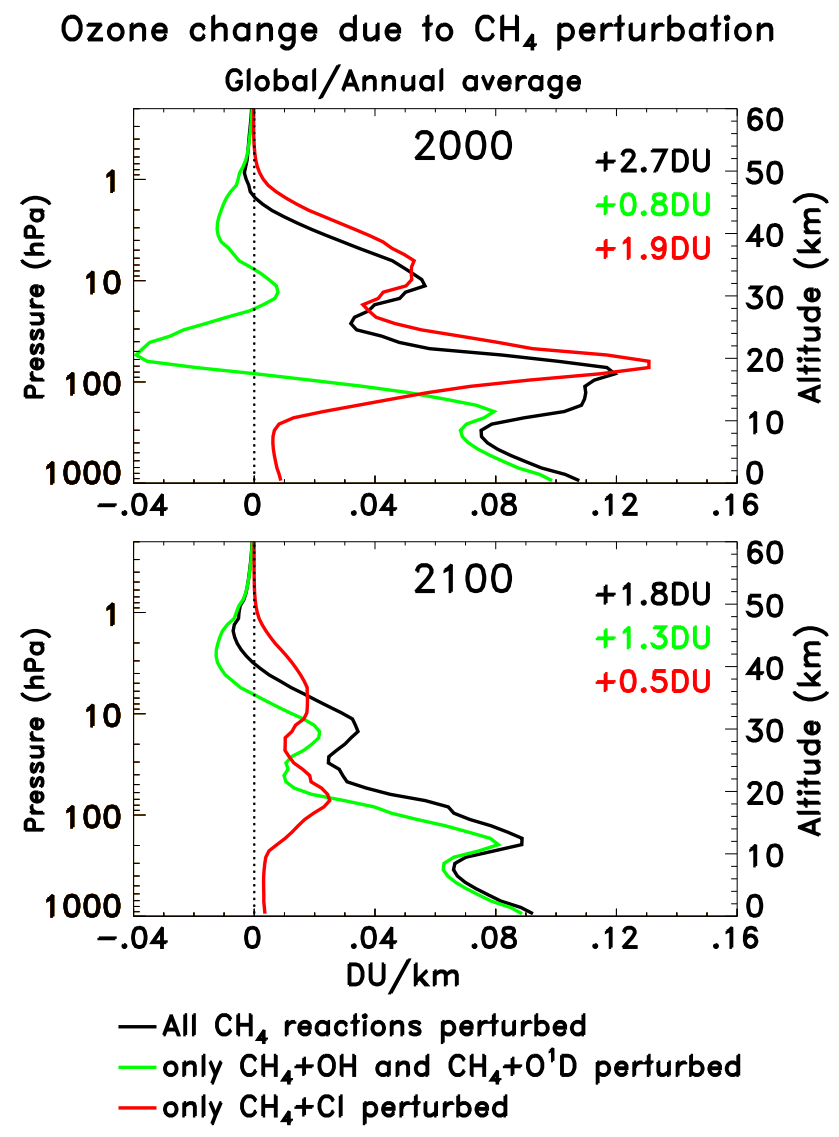

Fig. 9. Vertical profiles of the annual and global averaged steady state ozone change (DU km${ }^{-1}$ ) due to a $0.5 \mathrm{ppmv} \mathrm{CH}_{4}$ perturbation for year 2000 (top) and year 2100 (bottom). The black curves show simulations with all $\mathrm{CH}_{4}$ reactions (reactions with $\mathrm{O}\left({ }^{1} \mathrm{D}\right), \mathrm{OH}$, and Cl) using perturbed $\mathrm{CH}_{4}$. The green curves show simulations using perturbed $\mathrm{CH}_{4}$ for reactions with $\mathrm{O}\left({ }^{1} \mathrm{D}\right)$ and $\mathrm{OH}$, with unperturbed $\mathrm{CH}_{4}$ used for the reaction $\mathrm{CH}_{4}+\mathrm{Cl}$. The red curves show simulations using perturbed $\mathrm{CH}_{4}$ for the reaction $\mathrm{CH}_{4}+\mathrm{Cl}$ with unperturbed $\mathrm{CH}_{4}$ used for reactions with $\mathrm{O}\left({ }^{1} \mathrm{D}\right)$ and $\mathrm{OH}$. The total column responses for each case are listed in the upper right corner of each panel.

To qualitatively separate the effects of the different chemical mechanisms, the green curve is a simulation in which the perturbed $\mathrm{CH}_{4}$ is used for the reactions with $\mathrm{O}\left({ }^{1} \mathrm{D}\right)$ and $\mathrm{OH}$, with unperturbed $\mathrm{CH}_{4}$ used for the reaction $\mathrm{CH}_{4}+\mathrm{Cl}$. To do this, we compute the $\mathrm{CH}_{4}+\mathrm{Cl}$ reaction at all model grid points using the perturbed $\mathrm{CH}_{4}$ multiplied by the ratio of the unperturbed/perturbed $\mathrm{CH}_{4}$ boundary conditions $(1.75 / 2.25 \mathrm{ppmv})$. In this way, the conversion of active chlorine $(\mathrm{Cl})$ to the reservoir $(\mathrm{HCl})$ is not impacted by the perturbed $\mathrm{CH}_{4}$. Therefore, ozone only responds to the enhanced $\mathrm{NO}_{\mathrm{x}}$-induced ozone production in the troposphere yielding ozone increases in this region, and the enhanced $\mathrm{H}_{2} \mathrm{O}$ and $\mathrm{HO}_{\mathrm{x}}$-ozone loss cycles above $\sim 35 \mathrm{~km}$ and in the very lower stratosphere, which yield ozone decreases. The enhanced 
$\mathrm{H}_{2} \mathrm{O}$ in this case also enhances polar stratospheric clouds and the heterogeneous chemical ozone loss in the SH polar region, which contributes to the negative response at $17-28 \mathrm{~km}$ in the global average in Fig. 9.

The red curve in Fig. 9 shows the opposite case of the green curve, i.e., here, perturbed $\mathrm{CH}_{4}$ is used for the reaction $\mathrm{CH}_{4}+\mathrm{Cl}$, with unperturbed $\mathrm{CH}_{4}$ (adjusted as described above) used for the reactions with $\mathrm{O}\left({ }^{1} \mathrm{D}\right)$ and $\mathrm{OH}$. This significantly reduces the amount of $\mathrm{H}_{2} \mathrm{O}$ and $\mathrm{HO}_{\mathrm{x}}$-ozone loss, as well as the $\mathrm{NO}_{\mathrm{x}}$-ozone production in the troposphere generated by the $\mathrm{CH}_{4}$ perturbation. This better isolates the impact of $\mathrm{CH}_{4}$ in controlling the chlorine partitioning and subsequent chlorine-catalyzed ozone loss. The resulting ozone response is positive throughout the stratosphere, with the largest impacts occurring in the regions where chlorinecatalyzed ozone destruction is largest, i.e., the upper stratosphere globally, and in the lower stratosphere corresponding to the ozone hole region. Comparing the green and red curves shows that the $\mathrm{CH}_{4}+\mathrm{Cl}$ reaction has the largest impact on ozone at $\sim 15-45 \mathrm{~km}$, with the $\mathrm{NO}_{\mathrm{x}}$-ozone production mechanism being dominant below $15 \mathrm{~km}$.

The bottom panel in Fig. 9 shows the same cases run for 2100 conditions, which has greatly reduced chlorine loading compared with present day conditions. The effect of the future reduced chlorine loading is evident, as the case in which the perturbed $\mathrm{CH}_{4}$ is used only for the $\mathrm{CH}_{4}+\mathrm{Cl}$ reaction (red curve) exhibits a much weaker ozone response at all levels compared with the simulations for present day conditions. For the total column, this simulation accounts for only $28 \%$ of the full $\mathrm{CH}_{4}$ response $(+1.8 \mathrm{DU})$ in 2100 , compared to $70 \%$ of the full response in 2000. In 2100, the full ozone response to the $\mathrm{CH}_{4}$ perturbation (black curve) is dominated below $\sim 18 \mathrm{~km}$ by the enhanced $\mathrm{NO}_{\mathrm{x}}$-ozone production, and above $\sim 45 \mathrm{~km}$ by the enhanced $\mathrm{HO}_{\mathrm{x}}$-ozone loss.

For time dependent total ozone, the combined effect of $\mathrm{CH}_{4}$ and $\mathrm{Cl}_{\mathrm{y}}$ loading is illustrated in Fig. 6. The solid orange curve (2-D-CH $\mathrm{CH}_{4}$ only) uses fixed 1850 (very low) chlorine loading, and is therefore similar to the green curves in Fig. 9 (unperturbed $\mathrm{CH}_{4}+\mathrm{Cl}$ ) since the impact of the $\mathrm{CH}_{4}+\mathrm{Cl}$ reaction is minimal in this case. To illustrate the full effect of $\mathrm{CH}_{4}$ in the presence of time dependent ODS loading (analogous to the black curves in Fig. 9), the 2-D-CH 4 only(a) curve (orange dashed-dotted in Fig. 6) is the difference between a simulation with $\mathrm{CH}_{4}$ and the ODSs varied time dependently and that with only the ODSs varied time dependently $\left(\mathrm{CO}_{2}\right.$ and $\mathrm{N}_{2} \mathrm{O}$ are fixed at 1850 levels in both simulations). Compared to the simulation using fixed $1850 \mathrm{Cl}_{\mathrm{y}}$ (solid orange line), the full effect of $\mathrm{CH}_{4}$ loading results in significantly more global total ozone when the ODS loading is highest, i.e., $\sim 1985$ through the first half of the 21 st century.

This effect can also be seen in the ODS-only simulation, i.e., the effect of ODS loading in the presence of time dependent $\mathrm{CH}_{4}$ (the 2-D-ODS only(b) curve (blue dashed-dotted) in Fig. 6). This is the difference between the simulation with
Table 1. Steady state 2-D model calculated annual/global average flux $\left(\mathrm{kg} \mathrm{s}^{-1}\right)$ required to produce a $1 \%$ change in annually averaged global total ozone for the compounds and years listed. The ozone change is negative for CFC- 11 and $\mathrm{N}_{2} \mathrm{O}$, and positive for $\mathrm{CH}_{4}$ and $\mathrm{CO}_{2}$.

\begin{tabular}{lrrrr}
\hline & 1850 & 1950 & 2000 & 2100 \\
\hline $\mathrm{CFC}-11$ & 1.52 & 1.65 & 2.02 & 1.83 \\
$\mathrm{~N}_{2} \mathrm{O}$ & 61.9 & 68.5 & 107 & 104 \\
$\mathrm{CH}_{4}$ & 4980 & 4960 & 3130 & 5960 \\
$\mathrm{CO}_{2}$ & 241 & 269 & 519 & 881 \\
\hline
\end{tabular}

$\mathrm{CH}_{4}$ and the ODSs varied time dependently and that with only $\mathrm{CH}_{4}$ varied time dependently. Comparing the two blue curves illustrates how the impact of the ODS loading (i.e., $\mathrm{Cl}_{\mathrm{y}}$ ) is mitigated by the time dependent $\mathrm{CH}_{4}$ changes. This effect is largest when the ODS loading is largest, i.e., 2000, when the global total ozone depletion due to ODS loading is $3 \mathrm{DU}(1 \%)$ less in the presence of the time dependent $\mathrm{CH}_{4}$ changes compared to that with fixed $1850 \mathrm{CH}_{4}$ levels.

\subsection{Quantification of the ozone impacts due to GHGs}

Given the importance of increasing GHG emissions on future ozone levels, we examine these relative impacts in more quantitative detail. To do this, we apply the concept of the Ozone Depletion Potential (ODP) to GHG emissions, as recently done for $\mathrm{N}_{2} \mathrm{O}$ and the induced $\mathrm{NO}_{\mathrm{x}}$-ozone destruction (Ravishankara et al., 2009; Daniel et al., 2010). Traditionally, the ODP metric has been used to quantify the change in global ozone per unit mass emission of a specific chlorinecontaining compound relative to the change in global ozone per unit mass emission of CFC-11 $\left(\mathrm{CFCl}_{3}\right)$ (Wuebbles, 1983; Fisher et al., 1990; Solomon et al., 1992). Because the ODP is defined as a ratio to the ozone loss due to CFC-11, many uncertainties in the ozone-loss computation cancel. For this reason ODPs of chlorocarbon compounds are generally less sensitive to photochemical modelling uncertainties than are absolute ozone loss calculations.

Application of the ODP concept to a non-chlorine containing compound does not benefit in the same way from the cancellation of uncertainties in the ratio of ozone loss to that of CFC-11, e.g., $\mathrm{N}_{2} \mathrm{O}$ does not cause an ozone hole. More generally, the chemical mechanisms that impact ozone are different for GHGs, and tend to occur in different regions of the atmosphere, compared to those of chlorine containing compounds.

While being cautious about the interpretation of the ODP concept as applied to non-chlorine containing compounds, we use the ODP metric to examine the relative impacts on ozone of $\mathrm{N}_{2} \mathrm{O}, \mathrm{CH}_{4}, \mathrm{CO}_{2}$, and $\mathrm{CFC}-11$ for 1850,1950 , 2000, and 2100 steady-state atmospheric conditions. These 
Table 2. Steady state 2-D model calculated ozone depletion potential (ODP) relative to $\mathrm{CFC}-11$ for $\mathrm{N}_{2} \mathrm{O}, \mathrm{CH}_{4}$, and $\mathrm{CO}_{2}$ for the years indicated, based on the values listed in Table 1 .

\begin{tabular}{rrrrr}
\hline & 1850 & 1950 & 2000 & 2100 \\
\hline $\mathrm{N}_{2} \mathrm{O}$ & +0.025 & +0.024 & +0.019 & +0.018 \\
$\mathrm{CH}_{4}$ & -0.00031 & -0.00033 & -0.00065 & -0.00031 \\
$\mathrm{CO}_{2}$ & -0.0063 & -0.0062 & -0.0039 & -0.0021 \\
\hline
\end{tabular}

Table 3. Steady state 2-D model calculated percentage change in annual/global average total ozone per unit mixing ratio change for the compounds and years listed. The mixing ratios are in parts per billion by volume (ppbv) for $\mathrm{N}_{2} \mathrm{O}$, and parts per million by volume (ppmv) for $\mathrm{CH}_{4}$ and $\mathrm{CO}_{2}$. Shown in parentheses are the percentage changes of each compound, relative to the background levels, required to produce a $1 \%$ ozone change.

\begin{tabular}{rrrrr}
\hline & 1850 & 1950 & 2000 & 2100 \\
\hline $\mathrm{N}_{2} \mathrm{O}$ & $-0.031(12)$ & $-0.028(13)$ & $-0.020(16)$ & $-0.021(13)$ \\
$\mathrm{CH}_{4}$ & $+1.8(70)$ & $+1.7(49)$ & $+2.6(22)$ & $+1.4(36)$ \\
$\mathrm{CO}_{2}$ & $+0.016(23)$ & $+0.014(23)$ & $+0.0077(34)$ & $+0.0041(33)$
\end{tabular}

calculations are meant as a guide for evaluating the relative importance of GHG loading on past and future ozone levels.

We use the standard method to calculate ODPs, i.e., change each species by an amount that leads to a $1 \%$ change in annually-averaged global total ozone. Table 1 shows the resulting annual and global average flux of each compound for the years indicated. The ozone change is negative for CFC-11 and $\mathrm{N}_{2} \mathrm{O}$, and positive for $\mathrm{CH}_{4}$ and $\mathrm{CO}_{2}$. Note that the flux changes for $\mathrm{N}_{2} \mathrm{O}, \mathrm{CH}_{4}$ and $\mathrm{CO}_{2}$ are much larger, by one to three orders of magnitude, than those for CFC11. Table 2 shows these numbers converted to the standard ODP, i.e., the ratio of the flux change needed to cause a $1 \%$ ozone change for each compound to the flux change for CFC-11. Our $\mathrm{N}_{2} \mathrm{O}$ ODP values for 1950 and $2000(+0.024$ and +0.019 , respectively), are similar to those reported in Ravishankara et al. (2009). These results also illustrate that while $\mathrm{N}_{2} \mathrm{O}$ has a positive $\mathrm{ODP}, \mathrm{CH}_{4}$ and $\mathrm{CO}_{2}$ have negative ODPs relative to CFC-11. However because the fluxes and ODPs vary by two orders of magnitude, and the background concentrations also undergo large changes, it is difficult to evaluate these values on an absolute basis or relative to one another.

Tables 3 and 4 illustrate another way to look at the problem of comparing the impact of GHGs on ozone. Table 3 shows the sensitivity of total column ozone to a specified change in the concentration of each GHG. These are expressed in percent change in ozone for a 1 parts per billion by volume (ppbv) or 1 ppmv change in the surface concentration of the GHGs. The impact of each can then be deduced by multiply-
Table 4. Percentage change in annual/global average total ozone for the compounds and time intervals listed, based on the sensitivity factors in Table 3 and the change in the surface boundary condition in the A1B scenario (Fig. 1). The $\mathrm{CH}_{4}$-induced ozone change is negative for 2080-2100 due to the decrease in the methane boundary condition during this time.

\begin{tabular}{lccc}
\hline & $1940-1960$ & $1980-2000$ & $2080-2100$ \\
\hline $\mathrm{N}_{2} \mathrm{O}$ & -0.12 & -0.30 & -0.15 \\
$\mathrm{CH}_{4}$ & +0.31 & +0.49 & -0.30 \\
$\mathrm{CO}_{2}$ & +0.07 & +0.25 & +0.34 \\
\hline
\end{tabular}

ing by the actual change in the concentration of the species over a given time period. This is similar to the method used in Stolarski et al. (2010) for temperature changes. The resulting percentage ozone changes for several 20 -yr periods are listed in Table 4. Note that the $\mathrm{CH}_{4}$-induced ozone change is negative for 2080-2100 since the methane boundary condition decreases during this time period (Fig. 1). These calculations illustrate that $\mathrm{CH}_{4}$ had the largest GHG impact on ozone during 1980-2000, owing partly to the large effect of high $\mathrm{Cl}_{\mathrm{y}}$ loading, with the $\mathrm{N}_{2} \mathrm{O}$ and $\mathrm{CO}_{2}$ impacts being roughly equal and opposite. The $\mathrm{CH}_{4}$ impact was also substantially larger than either $\mathrm{N}_{2} \mathrm{O}$ or $\mathrm{CO}_{2}$ during 1940-1960, reflecting the large relative changes in the $\mathrm{CH}_{4}$ boundary condition during this time. However at the end of the 21st century, the $\mathrm{CO}_{2}$ impact is projected to be the largest, and will be more than twice the magnitude of the $\mathrm{N}_{2} \mathrm{O}$ impact.

Listed in parentheses in Table 3 are the sensitivities as percent changes to the background levels of each GHG, required to produce a $1 \%$ ozone change. For $\mathrm{N}_{2} \mathrm{O}$, a $\sim 15 \%$ change in the background is required to cause a $1 \%$ change in ozone, compared to a $\sim 25-35 \%$ change for $\mathrm{CO}_{2}$, and $\sim 20-70 \%$ change for $\mathrm{CH}_{4}$.

The time dependence of the values in Tables 1-3 partly reflects the fact that as the background concentrations increase, more flux of a substance is required to produce a $1 \%$ ozone change. However, this time dependence also reveals interesting aspects of the interactions of the perturbations. For CFC11, increasing levels of $\mathrm{N}_{2} \mathrm{O}$ (and subsequently $\mathrm{NO}_{\mathrm{x}}$ ) and $\mathrm{CH}_{4}$ convert active chlorine to the reservoirs $\mathrm{ClONO}_{2}$ and $\mathrm{HCl}$, respectively, thereby reducing the efficiency of $\mathrm{ClO}_{\mathrm{x}}-$ ozone destruction.

For $\mathrm{N}_{2} \mathrm{O}$, the time dependence is partly due to the changing background $\mathrm{Cl}_{\mathrm{y}}$, i.e., with higher $\mathrm{Cl}_{\mathrm{y}}$ more $\mathrm{NO}_{\mathrm{x}}$ is tied up in $\mathrm{ClONO}_{2}$, thereby reducing the efficiency of the $\mathrm{NO}_{\mathrm{x}}-$ ozone loss. Other factors include: (1) the $\mathrm{CO}_{2}$ cooling of the stratosphere which results in greater chemical destruction of $\mathrm{NO}_{\mathrm{y}}$ (Rosenfield and Douglass, 1998), and therefore reduced $\mathrm{NO}_{\mathrm{x}}-\mathrm{O}_{3}$ loss; and (2) a general decrease in $\mathrm{O}\left({ }^{1} \mathrm{D}\right)$, by as much as $10 \%$, from $\sim 1970-2100$ throughout most of the stratosphere which results in less $\mathrm{NO}_{\mathrm{x}}$ production via the 
reaction $\mathrm{N}_{2} \mathrm{O}+\mathrm{O}\left({ }^{1} \mathrm{D}\right)$. As a result of these factors, our $\mathrm{N}_{2} \mathrm{O}$ ODP in 2100 is a bit smaller than in 2000. The $\mathrm{N}_{2} \mathrm{O}$ ODPs for 1850 and 1950 are very similar, as are the $\mathrm{CH}_{4}$ and $\mathrm{CO}_{2}$ ODPs, reflecting the small GHG and EESC-induced changes in the stratosphere prior to 1950 (Figs. 5 and 6).

The ozone impact of $\mathrm{CH}_{4}$ is strongly dependent on the atmospheric chlorine loading, via the reaction $\mathrm{CH}_{4}+\mathrm{Cl}$ which affects the partitioning of $\mathrm{Cl}_{\mathrm{y}}$ (e.g., Figs. 6 and 9). As a result, significantly less $\mathrm{CH}_{4}$ flux is required (Table 1) to get a $1 \%$ ozone increase in 2000 (large $\mathrm{Cl}_{\mathrm{y}}$ loading) compared to 1850 , 1950, and 2100 (small $\mathrm{Cl}_{\mathrm{y}}$ loading). Similarly, the $\mathrm{CH}_{4}$ perturbation as a percentage of the background (Table 3 ) is significantly smaller in 2000 compared to the other years. The resulting $\mathrm{CH}_{4}$ ODP is nearly twice the magnitude in 2000 compared to 1950,1950 , or 2100 . As discussed earlier, the $\mathrm{CH}_{4}$ results presented here do not account for changes in tropospheric $\mathrm{NO}_{\mathrm{x}}$ emissions (the model uses fixed present day $\mathrm{NO}_{\mathrm{y}}$ specified from the GMI simulations). These likely undergo significant past and future changes (IPCC, 2007), with less (more) $\mathrm{NO}_{\mathrm{x}}$ leading to less (more) tropospheric ozone production and a smaller (larger) negative $\mathrm{CH}_{4}$ ODP than we report in Table 2.

For $\mathrm{CO}_{2}$, the strong time dependence in Tables $1-3$ is mostly due to the changing background concentration, which increases by a factor of 2.5 from 1850-2100 (Fig. 1). However, the percentage change relative to the background in Table 3 is somewhat larger in 2000 and 2100 than in 1850 and 1950. This is partly due to the fact that $\mathrm{CO}_{2}$ cooling and the corresponding increase in upper stratospheric ozone become less efficient at higher $\mathrm{CO}_{2}$ levels, i.e., a saturation effect (e.g., Ramaswamy et al., 2001a). There are other higher order effects that influence this $\mathrm{CO}_{2}$ time dependence, including the future changing concentrations of polar stratospheric clouds (PSCs) - due to stratospheric cooling and increasing water vapor - coupled with the decreasing halogen loading.

\section{Temperature}

Previous studies have investigated stratospheric temperature trends in the recent past and future, including the relative contributions of ODS and GHG loading (e.g., Ramaswamy et al., 2001b; Shine et al., 2003; Shepherd and Jonsson, 2008; Stolarski et al., 2010). Here we briefly summarize the model simulated temperature changes, focussing on the relative contributions of $\mathrm{CO}_{2}, \mathrm{CH}_{4}$, and $\mathrm{N}_{2} \mathrm{O}$.

Figure 10 shows the globally and annually averaged temperature time series from the base GEOSCCM and 2-D model simulations as indicated. As an observational reference, we also show the NCEP reanalysis and reanalysis2 data at $20 \mathrm{~km}$ for $1958-2009$, and the new NASA Modern Era Retrospective-analysis for Research and Applications (MERRA) meteorological analyses (see the website: http://gmao.gsfc.nasa.gov/research/merra/) for 1979-2009 at 40 and $60 \mathrm{~km}$. To match the early years of the data and to ac-

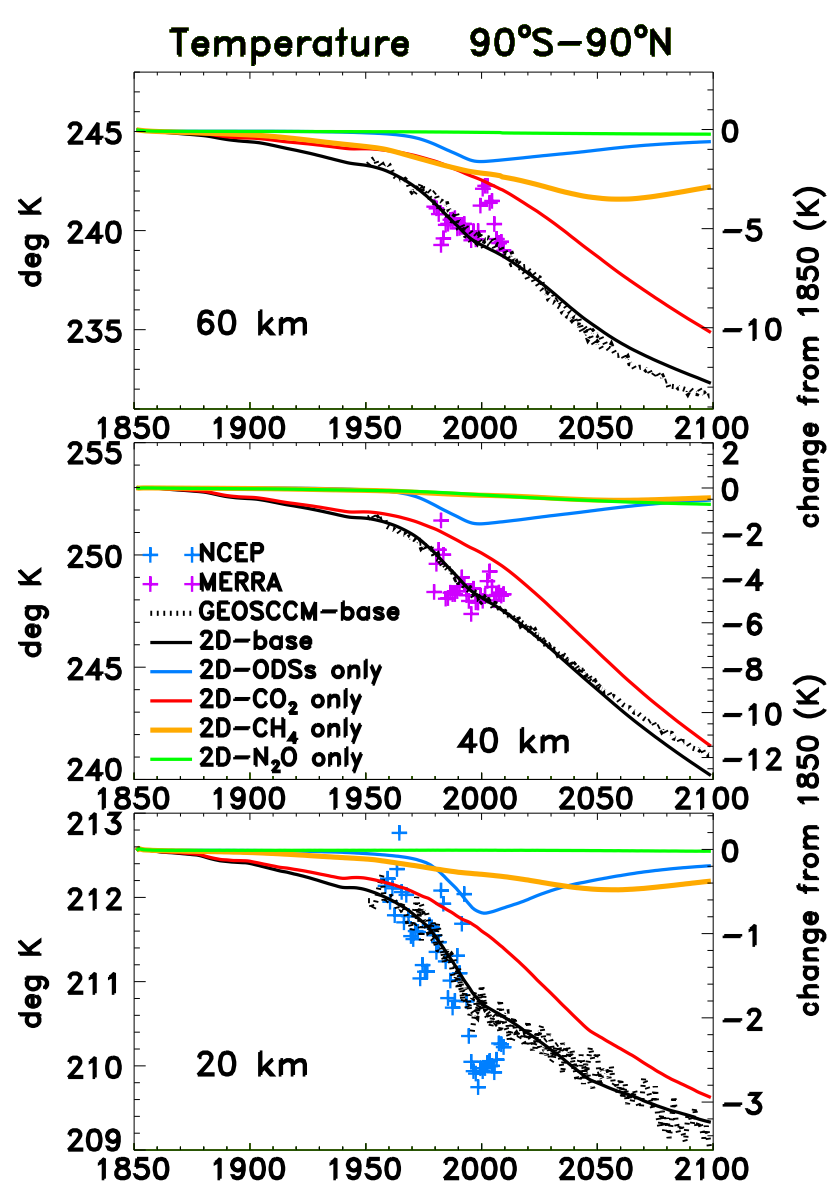

Fig. 10. Global and annually averaged temperature time series for $1850-2100$ at 20,40 , and $60 \mathrm{~km}$ from the base simulations (all source gases varied time dependently) of the GEOSCCM (black dotted lines) and 2-D model (black solid lines). Also shown are 2-D simulations in which only certain source gases are varied time dependently as follows: ODSs only (blue solid); $\mathrm{CO}_{2}$ only (red solid); $\mathrm{CH}_{4}$ only (orange solid); and $\mathrm{N}_{2} \mathrm{O}$ only (green solid), with the other source gases fixed at 1850 levels. The right hand axes show the changes relative to 1850 . The observations are from the NCEP reanalysis and reanalysis-2 data at $20 \mathrm{~km}$ for 1958-2009 (blue "+"), and the new NASA Modern Era Retrospective-analysis for Research and Applications (MERRA) meteorological analyses for 1979-2009 at 40 and $60 \mathrm{~km}$ (purple “+”). To account for the systematic differences between the models and data, we have added the following offsets to the models at 20,40 , and $60 \mathrm{~km}$, respectively: 2-D model: $0 \mathrm{~K},-3.4 \mathrm{~K},-1.5 \mathrm{~K}$; GEOSCCM: $-2.7 \mathrm{~K}$, $+1.3 \mathrm{~K},-2 \mathrm{~K}$.

count for the systematic differences between the models, the model curves have been offset as listed in the Fig. 10 caption. Although there is interannual variability in the data, the base models simulate the general rate of stratospheric cooling seen in the observations. Also, the 2-D and GEOSCCM base simulations have similar rates of cooling throughout 19502100 , consistent with the fact that both models utilize the same infrared (IR) radiative transfer schemes. Further model 
temperature trend comparisons are discussed in Appendix B (Figs. B2 and B3).

Following the time change in the surface boundary conditions (Fig. 1), the 2-D simulated temperature changes in Fig. 10 are significantly larger after $\sim 1970$ compared with the 1850-1970 time period. Prior to 1950, the temperature changes in the stratosphere are due almost entirely to the $\mathrm{CO}_{2}$ loading, with negligible impacts due to ODS and $\mathrm{N}_{2} \mathrm{O}$ loading. The temperature changes for 1850-1950 from the 2-D base run are mostly linear at 20, 40, and $60 \mathrm{~km}$, and are $-0.05 \mathrm{Kdecade}^{-1},-0.14 \mathrm{Kdecade}^{-1}$, and $-0.17 \mathrm{~K} \mathrm{decade}^{-1}$, respectively.

As discussed in previous studies, ODS loading and the corresponding reduction in ozone heating have a large impact on the temperature changes in the recent past, maximizing in the lower and upper stratosphere as seen in the vertical profiles in Fig. 11 (top). By 2100, $\mathrm{CO}_{2}$ cooling dominates the total temperature change throughout the stratosphere, and is significantly larger than the warming caused by the reduced ODS loading (Fig. 11, bottom).

The temperature impact of $\mathrm{N}_{2} \mathrm{O}$ caused by the associated $\mathrm{NO}_{\mathrm{x}}$-ozone depletion maximizes at $30-40 \mathrm{~km}$ but is relatively small $\left(-0.05 \mathrm{~K} \mathrm{decade}^{-1}\right.$ in Fig. 11$)$, corresponding to a cooling of $0.7 \mathrm{~K}$ from $1850-2100$ at $40 \mathrm{~km}$ (green curve in Fig. 10, middle).

Increases in $\mathrm{CH}_{4}$ induce temperature changes via several mechanisms. Below $\sim 18 \mathrm{~km}$, there is a slight warming (Fig. 11) caused by the combination of the direct IR radiative effect of $\mathrm{CH}_{4}$ and the indirect radiative effect of the resulting ozone increases in the troposphere and lower stratosphere (e.g., Portmann and Solomon, 2007). In the stratosphere, increases in $\mathrm{CH}_{4}$ lead to warming via the increases in ozone caused by the reduction of active chlorine by the the reaction $\mathrm{CH}_{4}+\mathrm{Cl} \rightarrow \mathrm{HCl}+\mathrm{CH}_{3}$. Increases in $\mathrm{CH}_{4}$ also lead to cooling in the stratosphere and mesosphere via the increases in water vapor. In the global average, the combination of these processes results in a net cooling above $\sim 20 \mathrm{~km}$ in Figs. 10-11.

In the lower mesosphere, the cooling effect of the $\mathrm{CH}_{4}$ induced $\mathrm{H}_{2} \mathrm{O}$ increases becomes large and is comparable to the $\mathrm{CO}_{2}$ cooling during 1850-2000 at $60 \mathrm{~km}$ (Fig. 10, top). By 2055 , the $\mathrm{CH}_{4}$-induced cooling is roughly half that due to the $\mathrm{CO}_{2}$ changes at $60 \mathrm{~km}$ in Fig. 10. We note also that the future $\mathrm{CH}_{4}$-induced temperature changes in Fig. 11 (bottom) are significantly smaller by 2095 compared to 2055 , following the decrease in the $\mathrm{CH}_{4}$ surface boundary condition during the latter half of the 21 st century in the A1B scenario (Fig. 1).

\section{Age of air}

Previous studies have shown that GHG loading and ozone depletion impact the stratospheric circulation and age of air (e.g., Butchart and Scaife, 2001; Austin and Li, 2006;

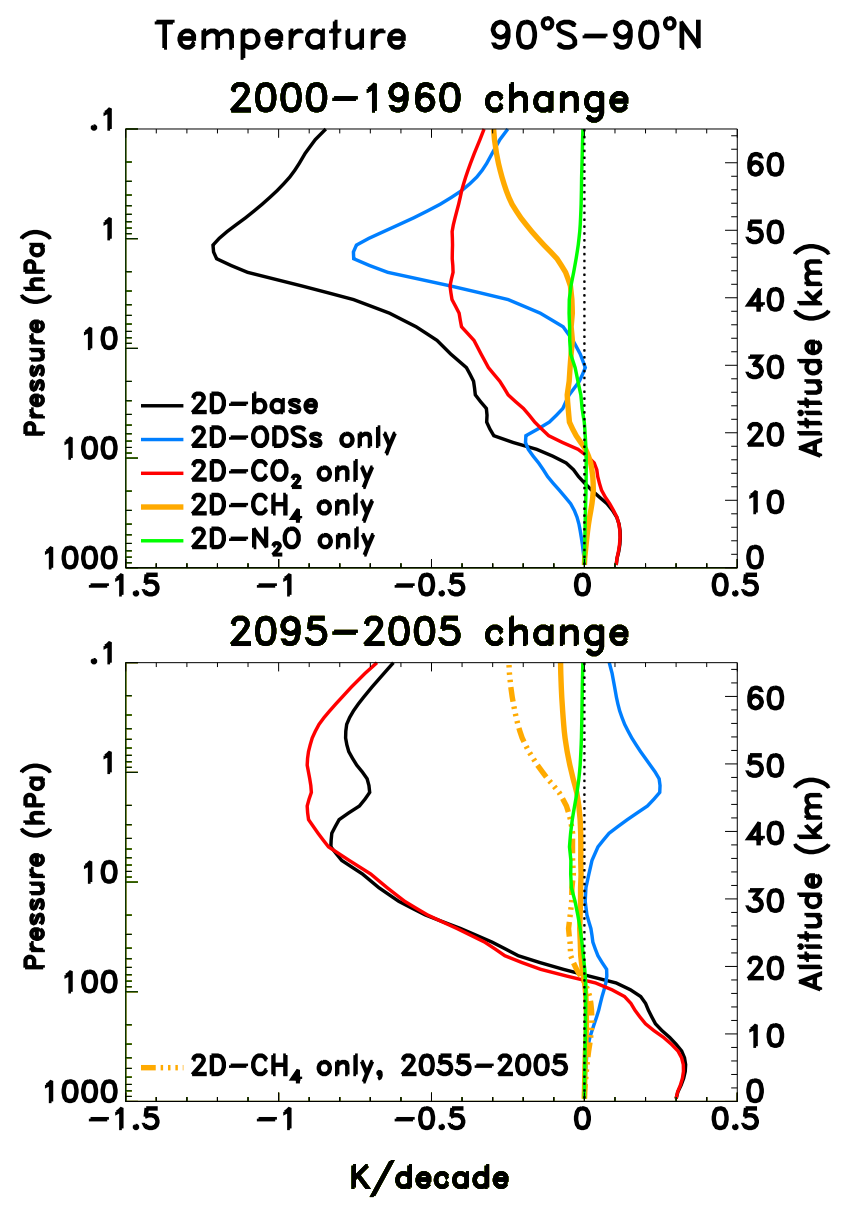

Fig. 11. (Top) Vertical profiles of the annual and global averaged temperature change (K decade ${ }^{-1}$ ) for 2000-1960 (top) and 20952005 (bottom) from 2-D model simulations as follows: base (black solid); ODSs only (blue solid); $\mathrm{CO}_{2}$ only (red solid); $\mathrm{CH}_{4}$ only (orange solid); and $\mathrm{N}_{2} \mathrm{O}$ only (green solid). In the bottom panel, the change due to $\mathrm{CH}_{4}$ is shown for 2095-2005 (orange solid) and 2055-2005 (orange dashed-dotted).

Butchart et al., 2006; Kodama et al., 2007; Garcia and Randel, 2008; Li et al., 2008; Oman et al., 2009). Although observations show little or no age trend over the past $30 \mathrm{yr}$ in the NH above $24 \mathrm{~km}$ (Engel et al., 2009), simulation of a general decrease in age through the 21 st century appears to be robust among coupled chemistry-climate models (SPARC CCMVal, 2010).

Here we briefly examine how the individual source gas perturbations used in this study impact the model age of air simulations. This is summarized in Fig. 12 (top panel), which shows time series of global and annually averaged age of air at $25 \mathrm{~km}$ from the various model simulations as indicated. The modeled age of air is computed from a "clock" tracer that has a surface boundary condition linearly increasing with time, with no other chemical production or loss (see Appendix B2 for more details). The results in Fig. 12 are 

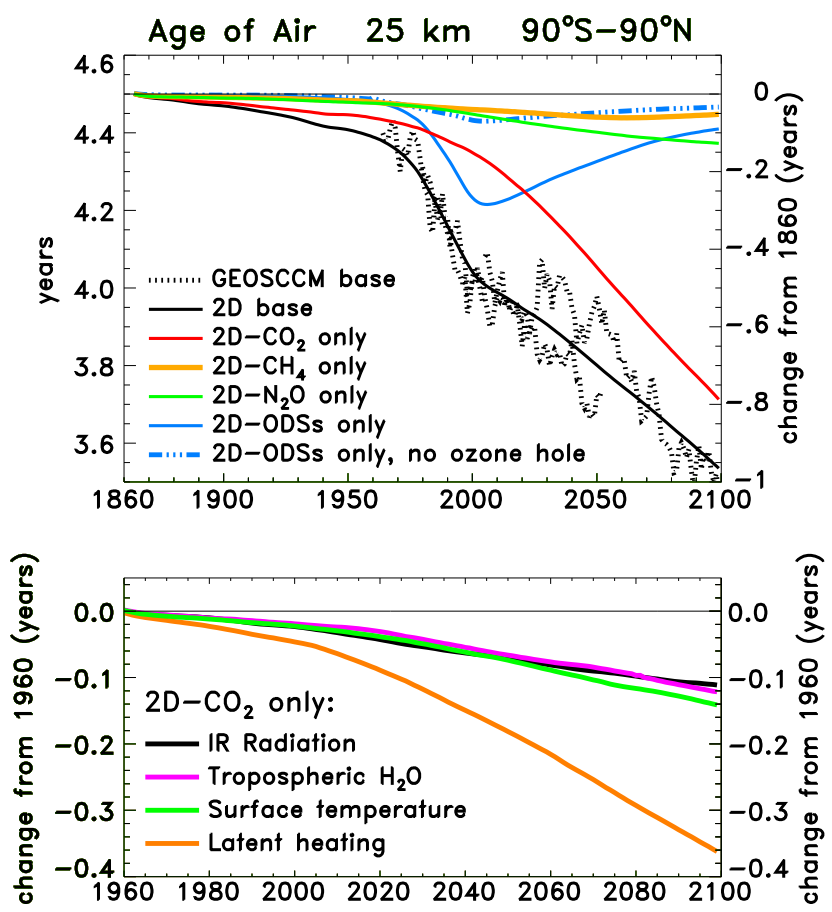

Fig. 12. Global and annually averaged age of air at $25 \mathrm{~km}$. (Top) Time series for 1860-2100 from the base simulations (all source gases varied time dependently) of the GEOSCCM (black dotted lines) and 2-D model (black solid lines). Also shown are 2-D simulations in which only certain source gases are varied time dependently as follows: $\mathrm{CO}_{2}$ only (red solid); $\mathrm{CH}_{4}$ only (orange solid); $\mathrm{N}_{2} \mathrm{O}$ only (green solid); and ODSs only (blue solid), with the other source gases fixed at 1850 levels. Also shown is a 2-D-ODS only simulation with all heterogeneous chemical reactions turned off so that no ozone hole is simulated (blue dashed-dotted). The right hand axis shows the change relative to 1860 . The GEOSCCM time series is comprised of three simulations, which use somewhat different SSTs, for the time periods 1950-2004, 1971-2052, and 1996-2100 (the first 8-10 yr of each simulation have been removed to allow for spin-up). For visual clarity and to account for a systematic offset between the models, we have added $0.3 \mathrm{yr}$ to the GEOSCCM curves. (Bottom) Time series for 1960-2100, relative to 1960 , from several 2-D-CO $\mathrm{CO}_{2}$ only simulations which use time dependent perturbations for the different processes as discussed in Fig. A1: IR radiation only (black solid); tropospheric $\mathrm{H}_{2} \mathrm{O}$ only (pink solid); surface temperature only (green solid); latent heating only (orange solid), with the other $\mathrm{CO}_{2}$ effects fixed at 1960 levels. The sum of the curves in the bottom panel equals the 2-D-CO $\mathrm{CO}_{2}$ only simulation (red curve) in the top panel. See text for details.

representative of altitudes above $\sim 20 \mathrm{~km}$. There is significant interannual variability in the GEOSCCM time series which is comprised of three simulations covering the periods 1950-2004, 1971-2052, and 1996-2100. However, the base 2-D and GEOSCCM simulations have similar rates of decrease in mean age over the 1960-2100 time period.
As with ozone and temperature, the 2-D-simulated changes in mean age are relatively small prior to 1950 , with $\mathrm{CO}_{2}$ loading accounting for about half of the total decrease of $0.1 \mathrm{yr}$ from 1860-1950. The base simulated age decreases much more rapidly after $\sim 1970$ when the impacts of $\mathrm{CO}_{2}$ and ODS loading become large and act in the same direction. The total age decrease is $0.3 \mathrm{yr}$ from 1980-2005, with $65 \%$ of this change due to ODS loading, $25 \%$ due to $\mathrm{CO}_{2}$, and $10 \%$ caused by $\mathrm{N}_{2} \mathrm{O}$ and $\mathrm{CH}_{4}$ changes. This dominance of the ODS loading is consistent with the GEOSCCM analysis of Oman et al. (2009). Figure 12 (top) also shows a 2-D-ODS only simulation with all heterogeneous chemical processes turned off, i.e., no ozone hole is simulated (blue dashed-dotted line). This simulation shows only small mean age change due to gas-phase chlorine-ozone destruction, and suggests that most of the ODS effect on the age of air change is due to the ozone hole. Separation of these ODS impacts on mean age is currently being investigated in the GEOSCCM (L. Oman, personal communication, 2011).

In the future, the base simulation age decreases less rapidly as the effects of the reduced ODS loading partially offset the $\mathrm{CO}_{2}$ impacts, with the latter becoming the dominant mechanism after about 2025. By 2100, $\mathrm{CO}_{2}$ loading accounts for $\sim 75 \%$ of the total age change $(\sim 1 \mathrm{yr})$ from 1860 . $\mathrm{N}_{2} \mathrm{O}, \mathrm{CH}_{4}$, and the remaining effects of ODS loading have secondary impacts by 2100 , with mean age decreases of 0.12 , 0.05 , and $0.08 \mathrm{yr}(12 \%, 5 \%$, and $8 \%$ of the total), respectively, from 1860-2100.

Previous studies have attributed the BDC acceleration to increased stratospheric wave driving resulting from changes in the zonal mean winds. These are ultimately due to changes in the temperature distribution induced by SST changes, GHG loading, and polar ozone depletion (e.g., Olsen et al., 2007; Kodama et al., 2007; Garcia and Randel, 2008; Oman et al., 2009). The 2-D model formulation uses parameterizations to account for planetary and gravity wave effects (Sect. A1), and the latitude-height patterns of the longterm changes in zonal mean temperature, zonal wind, waveinduced acceleration, lower stratospheric tropical upwelling, and age of air are generally similar to those in the Whole Atmosphere Community Climate Model version 3 (WACCM3) and GEOSCCM (Garcia and Randel, 2008; Oman et al., 2009). Therefore, it appears that the same basic characteristics of the CCM-simulated BDC and age of air changes are also present in the 2-D model.

The $\mathrm{CO}_{2}$ perturbation shown in Fig. 12 (top) modifies the model temperature field via the direct IR effect, and through changes in surface temperature, latent heating, and tropospheric $\mathrm{H}_{2} \mathrm{O}$ which are parameterized from the GEOSCCM (Fig. A1). These processes are likely due, at least in part, to the response of the GEOSCCM hydrological cycle to longterm SST changes. To examine the relative contributions of these processes to the 2-D model age evolution, we ran four additional time dependent $\mathrm{CO}_{2}$-only simulations in which the surface temperature, latent heating, tropospheric $\mathrm{H}_{2} \mathrm{O}$, 
and direct IR effect were varied individually, with the other $\mathrm{CO}_{2}$ effects held fixed at 1960 levels. The resulting age of air changes are shown in the bottom panel of Fig. 12, relative to 1960 values (we restrict our analysis here to the 19602100 time period when the age changes are largest). The increase in latent heating has by far the largest impact, contributing $\sim 50 \%(-0.36 \mathrm{yr})$ of the total $\mathrm{CO}_{2}$-induced mean age change ( $-0.73 \mathrm{yr}$ ) from 1960-2100. The impacts due to tropospheric $\mathrm{H}_{2} \mathrm{O}$ (purple line), surface temperature (green line), and the direct IR radiative effect (black line) are all a factor of $\sim 3$ smaller, with age changes of -0.1 to $-0.14 \mathrm{yr}$ from 1960-2100. The magnitude of the direct IR effect is similar to the GEOSCCM results reported in Oman et al. (2009). Note that the sum of the four curves in the bottom panel equals the full $\mathrm{CO}_{2}$-only simulation (red curve) in the top panel.

The ODS, $\mathrm{N}_{2} \mathrm{O}$, and $\mathrm{CH}_{4}$ perturbations shown in Fig. 12 (top) modify the 2-D model temperature field via the small direct IR radiative effect (lower atmospheric warming) and the larger indirect radiative effects caused by the induced ozone and $\mathrm{H}_{2} \mathrm{O}$ changes. These temperature changes modify the model zonal wind, wave driving, and BDC, which in turn drive the age of air changes shown in Fig. 12 (top).

The impact in the ODS-only simulation (blue solid curve) is driven mainly by the strong cooling trend during 19702000 associated with the ozone hole (Fig. B2), which induces a positive trend in zonal wind (increasing westerlies) at high SH latitudes. The accompanying trends (enhancements) in the planetary wave driving and BDC acceleration decrease the age of air. For the ODS-only simulation without the ozone hole (blue dashed-dotted curve), the ozone loss and cooling is confined to the upper stratosphere globally, with only small positive trends in zonal wind and wave driving at midlatitudes of both hemispheres, resulting in small BDC acceleration and age of air changes in Fig. 12.

\section{Photochemical lifetimes}

Given the significance of the long-term stratospheric changes caused by GHG and ODS loading, it is useful to examine how these changes impact the modeled photochemical lifetimes of certain compounds. The lifetime is important in determining the length of time over which a molecule of a substance will have a significant impact on ozone depletion or global warming, and in deriving surface mixing ratio boundary conditions from emissions estimates for use in atmospheric models (Kaye et al., 1994). The lifetime is computed as the atmospheric burden (total number of molecules) divided by the loss rate, both of which are vertically integrated and globally/annually averaged. We have recently shown the impact of new photolysis cross sections on the modelcomputed lifetime of $\mathrm{CCl}_{4}$ (Rontu Carlon et al., 2010). Here we examine the time dependence of the lifetimes of various compounds in more detail.

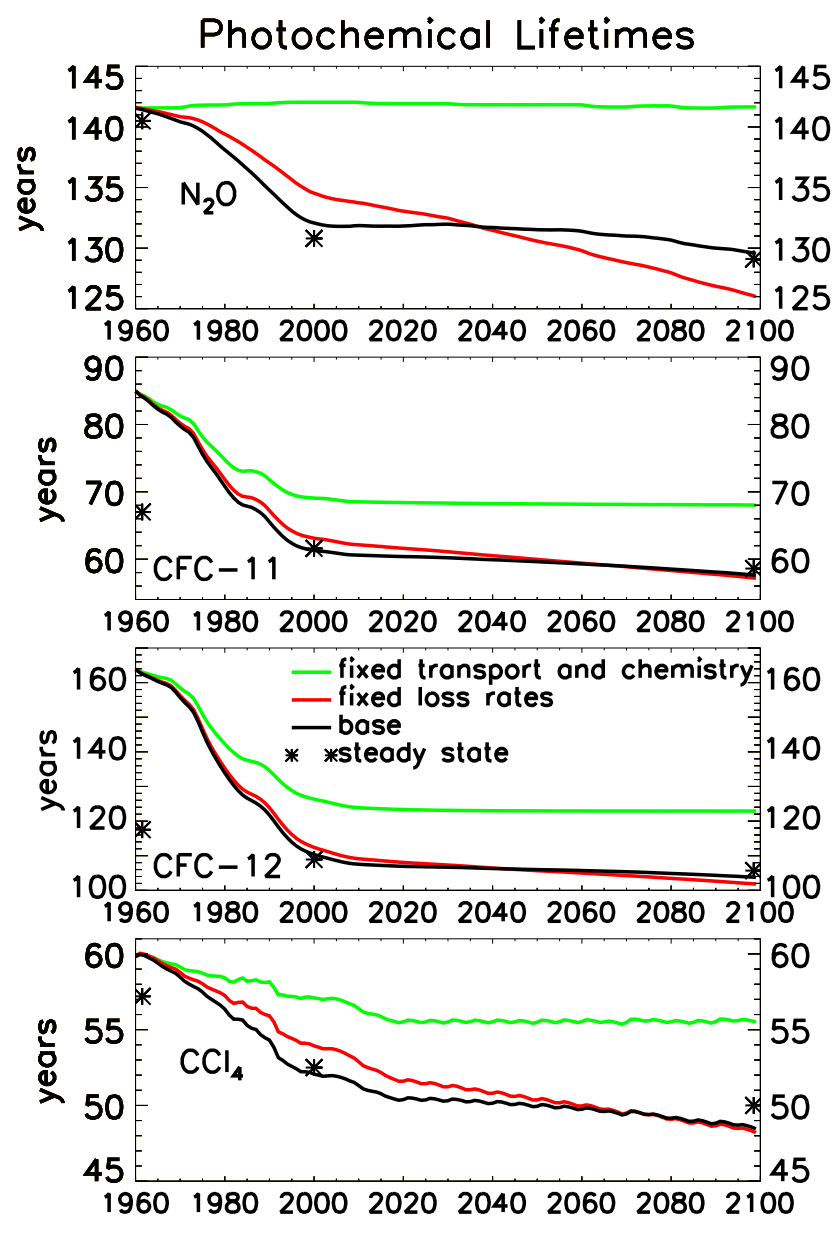

Fig. 13. Time series for $1960-2100$ of the photochemical lifetimes for $\mathrm{N}_{2} \mathrm{O}, \mathrm{CFC}-11\left(\mathrm{CFCl}_{3}\right), \mathrm{CFC}-12\left(\mathrm{CF}_{2} \mathrm{Cl}_{2}\right)$, and $\mathrm{CCl}_{4}$ from the base 2-D model simulation (black lines). The red lines are from the same base simulation except with the loss rates of $\mathrm{N}_{2} \mathrm{O}, \mathrm{CFC}-11$, CFC-12, and $\mathrm{CCl}_{4}$ fixed at seasonally repeating 1960 values. The green lines are from a simulation using all chemistry and transport fixed at seasonally repeating 1960 values illustrating the effect of the changing atmospheric burden. The asterisks depict the steady state lifetimes for 1960, 2000, and 2100.

Figure 13 (black lines) shows the modeled lifetimes of $\mathrm{N}_{2} \mathrm{O}, \mathrm{CFC}-11\left(\mathrm{CFCl}_{3}\right), \mathrm{CFC}-12\left(\mathrm{CF}_{2} \mathrm{Cl}_{2}\right)$, and $\mathrm{CCl}_{4}$ from the base 2-D simulation. We restrict our analysis here to the 1960-2100 time period since the CFC lifetimes are not well defined prior to 1960 given that emissions began in the late 1930s-1940s. While this is not a problem for $\mathrm{N}_{2} \mathrm{O}$ given that it has a significant natural source, the computed $\mathrm{N}_{2} \mathrm{O}$ lifetime decrease from 1860-1960 is small (143-141 yr), consistent with the small age of air decrease shown in Fig. 12.

The present day lifetimes shown in Fig. 13 (132, 61, 108 , and $51 \mathrm{yr}$, respectively, for $\mathrm{N}_{2} \mathrm{O}, \mathrm{CFC}-11, \mathrm{CFC}-12$, and $\left.\mathrm{CCl}_{4}\right)$, are older than those cited in $\mathrm{WMO}(2007,2011)$ and IPCC (2007): 114, 45, 100, and $26 \mathrm{yr}$. For $\mathrm{CCl}_{4}$, the older lifetimes shown here do not include soil or ocean loss 
processes. Updated lifetimes for CFC-11 and CFC-12 computed from various models (including the 2-D model) were presented in Douglass et al. (2008). That study illustrated a strong dependence of lifetime on the modeled circulation and age of air, and showed that models with realistic age of air simulated a relationship between mean age and the fractional release of CFC-11 and CFC-12 that compared well with observations. We note that the present 2-D model compares well with the age of air derived from observations in Fig. B4.

Figure 13 (green lines) also shows a simulation in which the time dependent loading of $\mathrm{N}_{2} \mathrm{O}, \mathrm{CFC}-11, \mathrm{CFC}-12$, and $\mathrm{CCl}_{4}$ impacts only the atmospheric burden used to compute the lifetimes, while the model transport and chemistry remain fixed at seasonally repeating 1960 values. This illustrates the effect of the changing burden on the computed lifetimes. As the surface mixing ratio of a substance increases with time, an increasing fraction of the total atmospheric burden resides in the stratosphere where it is lost, as opposed to the troposphere where the loss is zero, and this results in a decrease in the computed lifetime, i.e., the lifetime has not reached equilibrium with the increasing surface boundary conditions (e.g., see Kaye et al., 1994). For the CFCs, emissions began in the late 1930s-1940s and ramped up quickly during the following decades (Butler et al., 1999), so there is a large impact of the increasing burden on the lifetimes prior to $\sim 1990$. Atmospheric loading of $\mathrm{CCl}_{4}$ began $\sim 1900$ so that the influence of the increasing burden on the lifetime is small by 1960. This effect on the lifetimes of the $\mathrm{CFCs}$ and $\mathrm{CCl}_{4}$ then levels off as the burdens slowly decrease after 2000 , i.e., the lifetime has reached equilibrium with the boundary conditions. $\mathrm{N}_{2} \mathrm{O}$ has a significant natural source with a slow increase throughout 1960-2100 due to anthropogenic activity (Fig. 1), so the changing burden has little or no impact on the computed lifetime throughout the time period.

Figure 13 (asterisks) also shows the steady state lifetimes for 1960, 2000, and 2100 conditions. In steady state, the surface mixing ratio and stratospheric loss are in equilibrium (i.e., no burden effect). Therefore, the 1960 steady state lifetimes are susubstantially younger than the time dependent base lifetimes for the CFCs, with less of a difference for $\mathrm{CCl}_{4}$. The steady state and time dependent base lifetimes are very similar after $\sim 2000$ as the impact of the changing burden disappears in the time dependence. For $\mathrm{N}_{2} \mathrm{O}$, the impact of the burden is minimal throughout the time period as discussed above, so that the steady state and time dependent lifetimes are similar for 1960-2100.

The lifetimes are also controlled by the loss rates and the rate of transport of a species through the stratospheric loss region. The loss rates (photolysis and reaction with $\mathrm{O}\left({ }^{1} \mathrm{D}\right)$ ) are impacted by the overhead burden of ozone, and the transport rates are modified via changes in the BDC as discussed previously. Both of these processes incur long-term changes via the ODS and GHG loading.
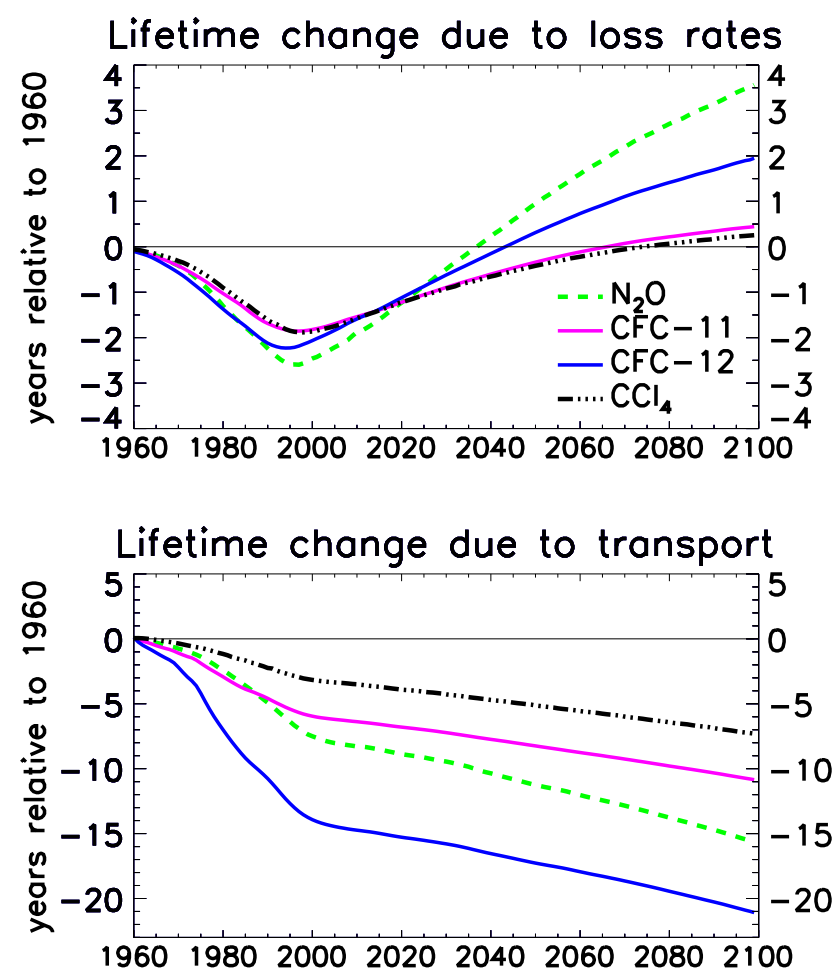

Fig. 14. (Top) The difference between the base and fixed loss rate simulations (black lines minus red lines in Fig. 13), illustrating the lifetime changes due to the changing loss rates. (Bottom) The difference between the fixed loss rate and fixed chemistry and transport simulations (red lines minus green lines in Fig. 13), showing the lifetime changes due to changes in transport. Shown are results for $\mathrm{N}_{2} \mathrm{O}$ (green dashed), CFC-11 (pink solid); CFC-12 (blue solid), and $\mathrm{CCl}_{4}$ (black dashed-dotted).

The red curves in Fig. 13 are the same as the base simulation except with the loss rates of $\mathrm{N}_{2} \mathrm{O}, \mathrm{CFC}-11, \mathrm{CFC}-12$, and $\mathrm{CCl}_{4}$ fixed at seasonally repeating 1960 values. The effect of the changing loss rates is then isolated by taking the difference between the base and fixed loss rate simulations (black lines minus red lines), i.e., the residual is that due to only the changing loss rates. The results are shown relative to 1960 in Fig. 14 (top) and reveal small impacts for all four species. These differences approximately follow the changing overhead burden of ozone, with lifetime decreases of $\sim 2 \mathrm{yr}$ (i.e., loss rate increase) for all species from 1960-2000 as ozone decreases due to ODS loading. As future ozone increases with reduced ODS and increased $\mathrm{CO}_{2}$, the impact of the loss rates during 2000-2100 increases the lifetimes by $6 \mathrm{yr}$ for $\mathrm{N}_{2} \mathrm{O}, 4 \mathrm{yr}$ for CFC-12, and $2 \mathrm{yr}$ each for CFC- 11 and $\mathrm{CCl}_{4}$. These changes are all $<4 \%$ over the 1960-2100 time period. This small impact of the changing loss rates was also reported in Douglass et al. (2008).

The effect of the changing BDC is isolated by taking the difference between the fixed loss rate and fixed chemistry and transport simulations (red lines minus green lines), i.e., 
the residual is that due to only the changing transport. These results are shown in the bottom panel of Fig. 14, again relative to 1960. The lifetime decreases are largest during 19602000 when the BDC acceleration is fastest (Fig. 12), with less pronounced decreases after 2000 as the BDC accelerates more slowly. The net lifetime reductions for 1960-2100 due to the changing $\mathrm{BDC}$ are all 11-13\%: $16 \mathrm{yr}$ for $\mathrm{N}_{2} \mathrm{O}, 11 \mathrm{yr}$ for CFC-11, $21 \mathrm{yr}$ for CFC-12, and $7 \mathrm{yr}$ for $\mathrm{CCl}_{4}$.

These changes in the loss rates and acceleration of the BDC also induce the changes in the steady state lifetimes from 1960-2100 seen in Fig. 13.

\section{Summary and conclusions}

We have used an updated version of our GSFC 2-D coupled model to study long-term stratospheric changes caused by source gas loading for the 250-yr time period, 1850-2100. Sensitivity simulations enable us to separate the relative roles of ODSs, $\mathrm{CO}_{2}, \mathrm{CH}_{4}$, and $\mathrm{N}_{2} \mathrm{O}$ in driving long-term changes in ozone, temperature, and age of air. We also compare the 2-D simulations with global ozone and temperature changes observed during the recent past, and with simulations from the GEOSCCM. These comparisons illustrate that the updated 2-D model captures the basic processes that drive longterm stratospheric changes.

For ozone, the impacts due to ODSs, $\mathrm{CO}_{2}, \mathrm{CH}_{4}$, and $\mathrm{N}_{2} \mathrm{O}$ all play important roles in different regions of the atmosphere, and the effects of the GHGs will become more important through the 21 st century as ODS emissions diminish. $\mathrm{N}_{2} \mathrm{O}$ loading and the subsequent increase in odd nitrogen species lead to a maximum global ozone loss of $\sim 0.5 \%$ decade $^{-1}$ near $35 \mathrm{~km}$, with a global total column decrease of $2.7 \%$ from $1850-2100 . \mathrm{CH}_{4}$ loading impacts ozone via several processes, with the net effect being an increase in the total column at all latitudes and a global total ozone increase of $2.5 \%$ from $1850-2050$. This methane response is strongly dependent on $\mathrm{Cl}_{\mathrm{y}}$, so that the global total ozone response for present day conditions is significantly larger $(+2.5 \%)$ when $\mathrm{CH}_{4}$ loading is coupled with time dependent ODS changes, compared to a $+1.5 \%$ response calculated with very low (1850) levels of $\mathrm{Cl}_{\mathrm{y}}$. In the lower mesosphere, the $\mathrm{CH}_{4}$-induced $\mathrm{HO}_{\mathrm{x}}$-ozone loss dominates the ozone time dependence. This process resulted in significant ozone reductions prior to 1960 , so that one-third of the total decrease in ozone during 1850-2050 occurred by 1960 .

The net $\mathrm{CO}_{2}$ impact on total ozone is a decrease in the tropics and an increase in the global average and at midlatitudes, with a larger enhancement in the NH. For 1850$2100, \mathrm{CO}_{2}$ loading causes global ozone increases in the upper stratosphere and total column of $20 \%$ and $4.2 \%$, respectively. Our simulations indicate that compared with $\mathrm{N}_{2} \mathrm{O}$, $\mathrm{CH}_{4}$, and the ODSs, $\mathrm{CO}_{2}$ loading will have the largest impact on global total ozone in year 2100, and will have twice the magnitude of the $\mathrm{N}_{2} \mathrm{O}$ impact, based on the IPCC A1B scenario.
Prior to 1960 , the simulated ozone changes are relatively small, but are not insignificant. $\mathrm{N}_{2} \mathrm{O}$ loading caused a $0.5 \%$ decrease in global total ozone from 1860-1960, and ODS emissions, primarily due to carbon tetrachloride, caused $1 \%$ depletion from $\sim 1900-1960$. However, these losses were outpaced by the $\mathrm{CO}_{2}$ - and $\mathrm{CH}_{4}$-induced ozone increases, with the net result being a broad maximum in total column and upper stratospheric ozone during the 1920s-1930s. This preceded the decline in ozone driven mainly by ODS loading, which became much more rapid after $\sim 1970$.

The simulated changes in stratospheric temperature for 1850-2100 are mostly controlled by $\mathrm{CO}_{2}$ cooling, with the reduced ozone heating caused by ODS loading also playing an important role from $\sim 1980$ through the first half of the 21st century. The impact of $\mathrm{CH}_{4}$ and $\mathrm{N}_{2} \mathrm{O}$ are relatively small below $\sim 45 \mathrm{~km}$. Above $\sim 50 \mathrm{~km}$ the cooling due to the $\mathrm{CH}_{4}$-induced $\mathrm{H}_{2} \mathrm{O}$ increases becomes significant, and the resultant temperature changes are comparable to those induced by the ODS and $\mathrm{CO}_{2}$ loading.

We use the GEOSCCM simulations to parameterize longterm changes in several tropospheric processes (surface temperature, latent heating, water vapor) in the 2-D model. This enables the 2-D model to simulate long-term changes in the BDC and age of air which are similar to the GEOSCCM. The 2-D simulations indicate that for 1980-2005, most (65\%) of the age of air decrease was driven by ODS loading and the subsequent formation of the ozone hole. However for the 1860-2100 time period, most $(\sim 75 \%)$ of the $1 \mathrm{yr}$ age decrease was caused by $\mathrm{CO}_{2}$ loading, with $\mathrm{N}_{2} \mathrm{O}, \mathrm{CH}_{4}$, and ODS loading inducing much smaller age reductions $(12 \%$, $5 \%$, and $8 \%$, respectively).

The long-term BDC acceleration had a modest impact on the time dependent photochemical lifetimes of $\mathrm{N}_{2} \mathrm{O}, \mathrm{CFCl}_{3}$, $\mathrm{CF}_{2} \mathrm{Cl}_{2}$, and $\mathrm{CCl}_{4}$, causing lifetime decreases of $11-13 \%$ from 1960-2100. By comparison, long-term changes in the photolysis and $\mathrm{O}\left({ }^{1} \mathrm{D}\right)$ loss rates, due to stratospheric ozone changes, have a generally small impact on the lifetimes. This effect caused lifetime decreases of $\sim 2 \mathrm{yr}$ from 1960-2000, and increases of 2-6 yr (3-4\%) from 2000-2100.

\section{Appendix A}

\section{GSFC coupled 2-D model}

The GSFC 2-D coupled chemistry-radiation-dynamics model was originally discussed in Bacmeister et al. (1995) and has been frequently used in stratospheric assessments (WMO, 2007, 2011), and studies pertaining to the chemistryclimate coupling of the middle atmosphere (e.g., Rosenfield et al., 1997, 2002). While this model was not included in the recent CCMVal activity (SPARC CCMVal, 2010), several of the model components are very similar to those used in the GEOSCCM which was evaluated in CCMVal. These components include: the infrared (IR) radiative transfer scheme 
(Chou et al., 2001); the photolytic calculations (Anderson and Lloyd, 1990; Jackman et al., 1996); and the microphysical model for polar stratospheric cloud (PSC) formation (Considine et al., 1994). As discussed in Fleming et al. (2007), the model now uses an upgraded chemistry solver that computes a full diurnal cycle for 35 fast chemical constituents. This scheme was shown to be in good agreement with photochemical steady state box model calculations (Park et al., 1999). The latest Jet Propulsion Laboratory (JPL) recommendations are used for the photolytic cross sections and reaction rate constants (Sander et al., 2006).

The model domain extends from the ground to approximately $92 \mathrm{~km}$. The chemistry calculations are done on a grid resolution of $4^{\circ}$ latitude by $1 \mathrm{~km}$ altitude. We have found that for most applications, the model radiation and dynamics calculations can be adequately done on a somewhat coarser grid of $\sim 4.9^{\circ}$ latitude by $2 \mathrm{~km}$ altitude. Using a finer resolution only adds to the computational burden but does not improve the model dynamical simulations.

We have recently made extensive upgrades to the model solar radiation and dynamical modules, which are described in the following sections. An evaluation of the model temperature and transport are then provided in Appendix B.

\section{A1 Wave parameterizations}

The horizontal mixing $\left(K_{y y}\right)$ and momentum deposition due to dissipating planetary waves is computed using a linearized parameterization similar to that described by Garcia (1991). Previously, the parameterization used a surface boundary condition based on a representation of the topographic forcing of planetary waves. It was necessary to include adjustable amplitude efficiency factors for each wave number to obtain reasonable seasonal variations of the zonal winds and chemical fields (Rosenfield et al., 1997). In the present model, this lower boundary condition is based on a geopotential height climatology for $750 \mathrm{hPa}$ as a function of latitude and season, derived from the National Centers for Environmental Prediction (NCEP) reanalysis-2 data (Kistler et al., 2001) averaged over 1979-2007. This provides a more complete representation of the lower boundary forcing of planetary waves, e.g., land-ocean contrasts, in addition to the topographic forcing. We solve for planetary zonal wave numbers $1-4$. Compared to that obtained previously, the new methodology provides more realistic model simulations of planetary wave drag and mixing with no artificial wave amplitude adjustment factors necessary.

The model also includes the off-diagonal eddy diffusion of constituents $\left(K_{y z}\right)$, following the methodology used in our GSFC 2-D fixed transport model. This follows the assumption that horizontal eddy mixing is directed along the zonal mean isentropes, and projects the $K_{y y}$ mixing rates onto isentropic surfaces (Plumb and Mahlman, 1987; Newman et al., 1988).
The momentum deposition due to gravity wave breaking in the mesosphere is parameterized using a ray tracing calculation for waves with non-zero phase speeds, and a cubic drag law for zero-phase speed mountain waves (Bacmeister et al., 1995). This enables the gravity wave momentum flux to be interactive with the evolution of the zonal mean flow. However to obtain proper tracer simulations, we found it necessary to specify the model vertical eddy diffusion rates $\left(K_{z z}\right)$, which are taken from the GSFC 2-D fixed transport model as a function of latitude, height, and season (Fleming et al., 2007). For the upper stratosphere and mesosphere, these are based on the gravity wave parameterization originally developed by Lindzen (1981) and modified by Holton and Zhu (1984). For the troposphere and lower stratosphere, $K_{z z}$ is based on the zonal mean temperature lapse rate as computed from a multi-year average of NCEP reanalysis- 2 data.

\section{A2 Radiative transfer}

For the absorption of solar radiation in the ultraviolet and visible, we now compute the heating rates consistently with the model incident solar flux and photolysis calculations (Jackman et al., 1996). These are computed over a full diurnal cycle with a much finer spectral resolution compared to the broad band calculations used previously (Strobel, 1978; Chou and Suarez, 1999). These heating rate calculations have the further advantage of utilizing the most current recommendations for the photolytic cross sections (Sander et al., 2006). This new methodology also gives model temperatures that are in somewhat better agreement with observations.

For ozone, the heating rate in this way is computed by (e.g., Brasseur and Solomon, 1986):

$\frac{d T}{d t}=\frac{1}{\rho C_{\mathrm{P}}}\left(\mathrm{O}_{3}\right) \int_{\lambda} \sigma_{\left(\mathrm{O}_{3}\right)} F_{\mathrm{s}, \lambda} d \lambda$

where $\rho$ is the total atmospheric density, $C_{\mathrm{P}}$ is the specific heat of dry air at constant pressure, $\left(\mathrm{O}_{3}\right)$ is the ozone number density, $\lambda$ is the wavelength, $\sigma_{\left(\mathrm{O}_{3}\right)}$ is the ozone absorption cross section, and $F_{\mathrm{s}, \lambda}$ is the incident solar flux (enhanced or reduced) as a function of wavelength at each model grid point. In addition to ozone heating, we also include the heating due to absorption by $\mathrm{O}_{2}$, which is important in the mesosphere, and $\mathrm{NO}_{2}$ which is of secondary importance in the middle stratosphere. For these calculations, we assume that all of the solar radiation absorbed is immediately realized as thermal energy. This is a good approximation below $\sim 80 \mathrm{~km}$, i.e., the region of interest for the current study, where the chemical recombination of $\mathrm{O}\left({ }^{3} \mathrm{P}\right)$ is very fast (e.g., Brasseur and Solomon, 1986).

We also include the minor absorption of solar radiation by ozone in the IR, and by water vapor in the IR and visible based on the parameterization of Chou and Suarez (1999). For these calculations, we use surface reflectivity values as a function of latitude and season based on the TOMS climatology compiled by Herman and Celarier (1997). 


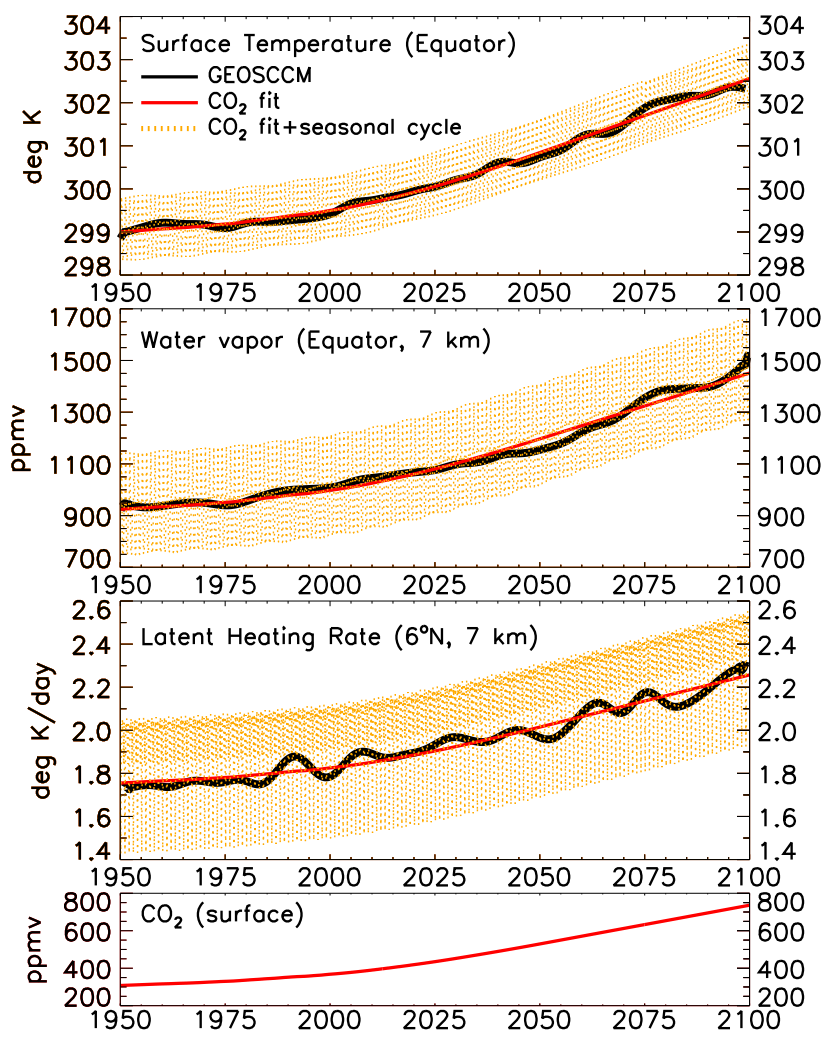

Fig. A1. Time series for 1950-2100 of zonally averaged and deseasonalized surface temperature, water vapor mixing ratio, and latent heating from the GEOSCCM (black curves), and the corresponding fits to the surface $\mathrm{CO}_{2}$ boundary condition (red curves) for the locations indicated. Inclusion of the seasonal cycle to the $\mathrm{CO}_{2}$ fits is depicted by the orange shading. The surface $\mathrm{CO}_{2}$ boundary condition is shown in the bottom panel. See text for details.

For the thermal infrared radiative transfer, we use the parameterization of Chou et al. (2001), which is the same as that used in the GEOSCCM. This includes the contributions due to $\mathrm{O}_{3}, \mathrm{CO}_{2}, \mathrm{H}_{2} \mathrm{O}, \mathrm{CH}_{4}, \mathrm{~N}_{2} \mathrm{O}, \mathrm{CFC}-11$, CFC-12, and HCFC-22. For both the solar and thermal IR calculations, the 2-D model includes zonally averaged cloud parameters based on output from the GEOSCCM.

\section{A3 Model treatment of longitudinal variations}

Previously, the model-generated zonal mean temperatures were used to compute the gas phase and heterogeneous reaction rates. In the new model version, reaction rates are now computed using a longitudinal temperature probability distribution which is generated from the model-computed planetary wave fields for zonal waves 1-4 (Sect. A1). The rates for the reactions at each model grid point are computed once per day by summing the rates computed for each temperature in the distribution weighted by the probability of occurrence of that temperature. Using the temperature probability distribution instead of the zonal mean temperature is especially important for the heterogeneous chemical reactions as these can have significant non-linearities in temperature.

For the calculation of PSC formation, we utilize the parameterization described in Considine et al. (1994), using longitudinal temperature probability distributions derived from the NCEP reanalysis-2 data averaged over 19792006. This climatological average distribution is used for all years in the simulations. This methodology does not allow for the interaction between PSC formation and the chemical/dynamical time evolution of the model stratosphere. However given the strong temperature non-linearity of PSC formation, we found it necessary to use the observed temperature distributions rather than the model temperatures to properly simulate PSC formation.

\section{A4 Tropospheric parameterizations}

Accounting for the hydrological cycle and surface boundary layer processes is important to properly simulate the dynamical and chemical distributions of the troposphere and lower stratosphere. Since the 2-D model framework is inadequate to simulate most tropospheric processes interactively, we specify the surface temperature, tropospheric water vapor and latent heating. As described in the following, we first generate monthly and zonal mean climatologies of these parameters, and then add on long-term changes parameterized in terms of the atmospheric $\mathrm{CO}_{2}$ loading.

The surface temperature seasonal cycle as a function of latitude is based on the NCEP reanalysis-2 data averaged over 1979-2006. Tropospheric latent heating as a function of latitude, height, and season is based on a multi-year average of output from WACCM3 simulations (e.g., Garcia et al., 2007). The model water vapor seasonal cycle in the upper troposphere $(12-16 \mathrm{~km})$ is based on the Upper Atmosphere Research Satellite (UARS) reference atmosphere (UARSRA) compiled by Randel et al. (2001). Below $12 \mathrm{~km}$, water vapor is derived from a $21 \mathrm{yr}$ average (1981-2001) of relative humidity data from the European Center for Medium-Range Weather Forecasts (ECMWF) updated reanalyses (ERA-40). Values from the UARSRA and ERA-40 data sets are functions of latitude, height, and season and are blended over several pressure levels to obtain a smooth transition in the vertical. Water vapor everywhere above the tropopause is computed in the 2-D model (see Fig. B6).

In addition to the seasonal variations, the surface temperature, tropospheric water vapor and latent heating undergo substantial long term changes as simulated by the GEOSCCM. This is illustrated in Fig. A1 which shows zonally averaged time series of GEOSCCM simulations for 1950-2100 (black curves) at the locations indicated. These time series have been deseasonalized and smoothed to reduce the interannual variability of the GEOSCCM. These long-term changes are highly correlated with the time dependent surface boundary condition of $\mathrm{CO}_{2}$ (bottom panel) and are likely a response to the warming of the troposphere 
and sea surface temperatures caused by the increased atmospheric $\mathrm{CO}_{2}$ loading. To represent these long-term changes in the 2-D model, we compute a sensitivity factor to the $\mathrm{CO}_{2}$ boundary condition for each parameter at each model grid point. The time dependent value of each parameter is then determined by the $\mathrm{CO}_{2}$ concentration at each time step multipled by the sensitivity factor. As depicted by the red curves in Fig. A1, this smoothly-varying fit to the $\mathrm{CO}_{2}$ boundary condition allows us to remove the unwanted artifacts of the GEOSCCM interannual variability. This also allows us to extrapolate these quantities to years prior to 1950 based on the $\mathrm{CO}_{2}$ loading, assuming the same sensitivity to $\mathrm{CO}_{2}$ as for 1950-2100. The orange shading in Fig. A1 shows the climatological seasonal cycle for each parameter added onto the long-term variation for input into the 2-D model.

\section{Appendix B}

\section{2-D model temperature and tracer comparisons}

In this Appendix, we provide an evaluation of the 2-D model transport fields by comparing the simulations with observations of several tracers including ozone. We also evaluate the model temperature simulations (climatology and trends).

\section{B1 Temperature}

The model temperature field for February is shown in Fig. B1, along with the MERRA meteorological analyses (Sect. 4), both averaged over 1979-2009. The largest model differences (bottom panel) occur at high SH latitudes in the upper troposphere $(-6 \mathrm{~K})$, and in the $\mathrm{NH}$ polar region at 20 $25 \mathrm{~km}(-6 \mathrm{~K})$ and above $45 \mathrm{~km}(+18 \mathrm{~K})$. However overall, the model is in reasonable agreement with the MERRA data, as the model differences are mostly within $\pm 5 \mathrm{~K}$.

The past and future temperature changes from the 2-D model and GEOSCCM are shown in Fig. B2. The 2-D model captures most of the latitude-height variations simulated in the GEOSCCM. The main discrepancies occur at high latitudes where the 2-D model somewhat underestimates the large temperature changes simulated by the GEOSCCM associated with the ozone hole, i.e., past cooling and future warming. Also, the GEOSCCM simulates a mid-upper stratospheric warming at high SH latitudes for 1960-2000, which was shown to be a dynamical response to the ozone hole (Stolarski et al., 2006). The 2-D model simulates this feature only very weakly (top right). These discrepancies are likely due to the 2-D model not fully resolving the large zonal asymmetries characteristic of the polar region, as well as the known high ozone bias at high latitudes in the GEOSCCM (Pawson et al., 2008).

The corresponding global average vertical profiles (Fig. B3) also show good agreement between the 2-D model and GEOSCCM as well as radiosonde data for 1960-2000
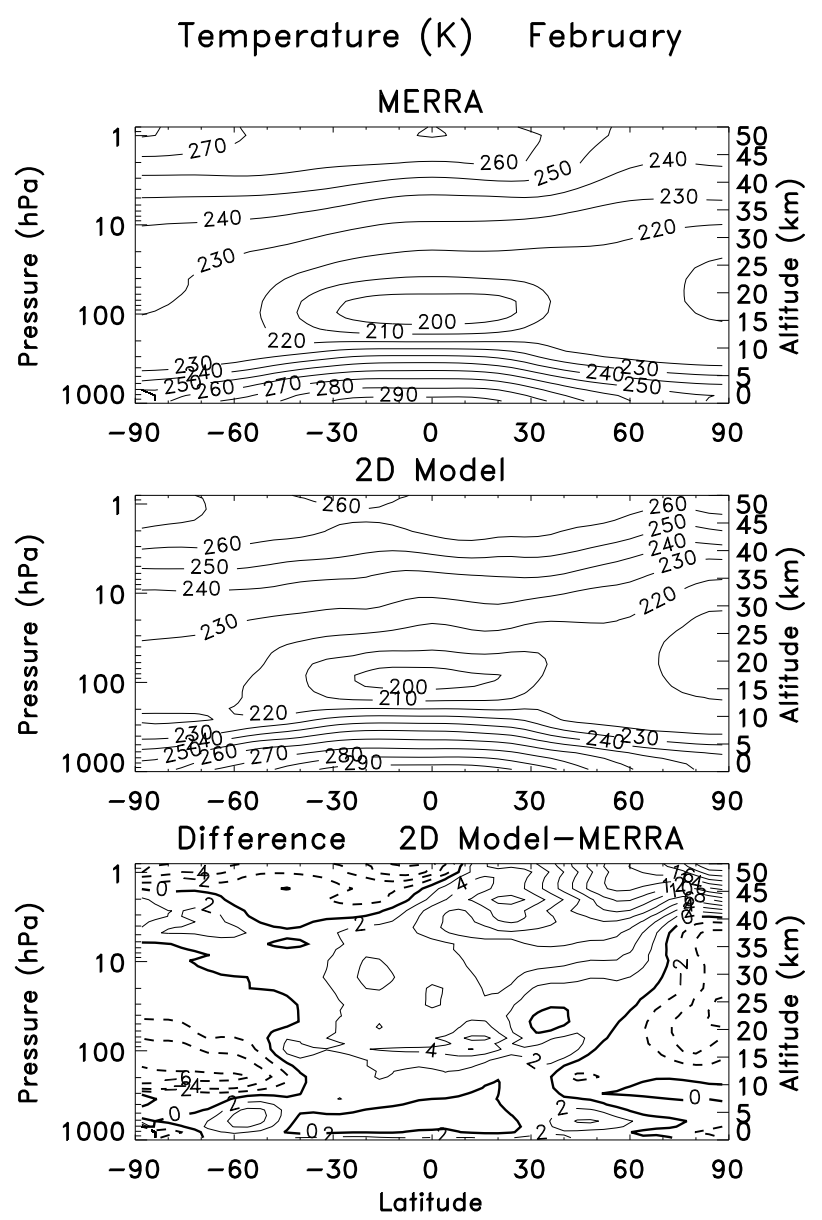

Fig. B1. Latitude-height cross-sections of the February monthly mean temperature (K) from the MERRA data (top), 2-D model simulation (middle), and the difference, model minus MERRA (bottom panel), all averaged over 1979-2009. The contour intervals are $10 \mathrm{~K}$ for the top and middle panels and $\pm 2 \mathrm{~K}$ for the bottom panel. The dashed contours in the bottom panel indicate negative differences.

from the Radiosonde Atmospheric Temperature Products for Assessing Climate (RATPAC-A) (Free et al., 2005). We note that the global average GEOSCCM stratospheric temperature trends were also found to be in reasonably good agreement with those derived from SSU and MSU satellite data for 1979-1999 (Stolarski et al., 2010).

In the troposphere, the 2-D model simulates warming throughout 1960-2100, which is due mainly to the parameterized long-term changes in surface temperature and latent heating shown in Fig. A1. The magnitude of the warming in the tropics is somewhat underestimated compared with the GEOSCCM in both the past and future (Fig. B2), although the 2-D-simulated warming over 1960-2000 compares favorably with the radiosonde data in the global average in Fig. B3. 


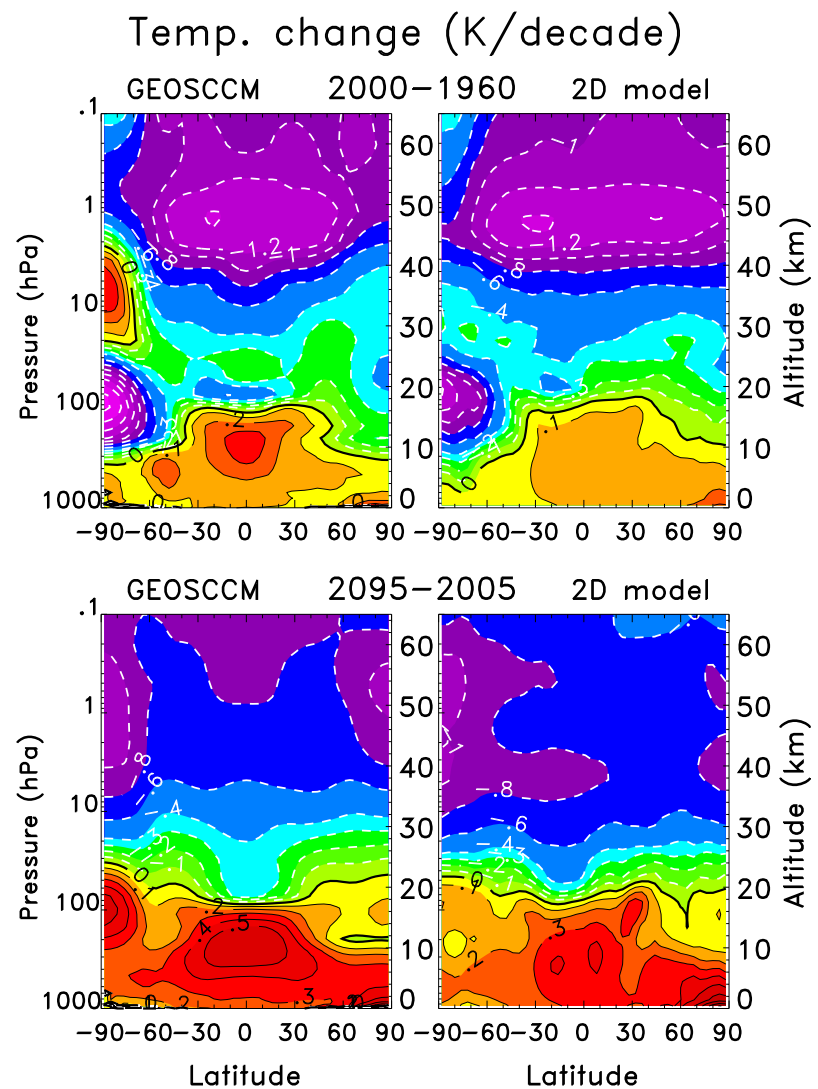

Fig. B2. (Top panels) Annually averaged temperature trend for 2000-1960 from the GEOSCCM (left) and 2-D model (right) base simulations (all source gases varied time dependently). The trends are derived from linear least squares fits to the annually averaged time series. (Bottom panels) As in the top panels except for the 2095-2005 temperature difference $\left(\mathrm{K} \mathrm{decade}^{-1}\right)$ using 10-yr averages centered on 2095 and 2005 to reduce the effects of interannual dynamical variability in the GEOSCCM. The contour intervals are -0.2 and $+0.1 \mathrm{~K}$ decade $^{-1}$ and include the -0.1 and -0.3 contours. The dashed contours indicate negative values.

\section{B2 Age of air}

Stratospheric age of air is a widely used diagnostic that tests the overall fidelity of model transport (e.g., Hall et al., 1999). Figure B4 shows the mean age of air at $20 \mathrm{~km}$ derived from aircraft measurements of $\mathrm{SF}_{6}$ (asterisks) and $\mathrm{CO}_{2}$ (triangles), and a series of vertical profile measurements of $\mathrm{SF}_{6}$ and $\mathrm{CO}_{2}$ made from balloon flights in three latitudes zones (e.g., see Hall et al., 1999). We note that differences in the observations at the middle and higher latitudes may reflect photochemical influences on $\mathrm{SF}_{6}$ which would cause an overestimation in the inferred ages (Hall and Waugh, 1998). Some of the older age measurements at $65^{\circ} \mathrm{N}$ may also reflect remnants of the winter polar vortex (Ray et al., 1999).

Figure B4 also shows the age of air derived from the 2-D model simulation averaged over the 1990s (red line). The

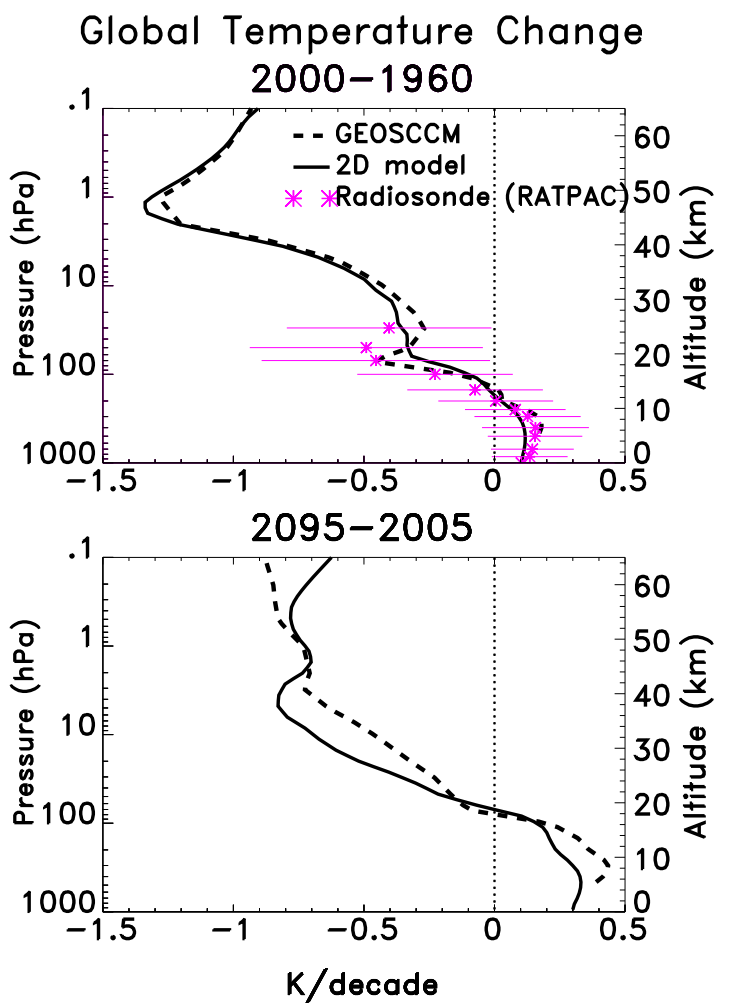

Fig. B3. As in Fig. B2, except for the global $\left(90^{\circ} \mathrm{S}-90^{\circ} \mathrm{N}\right)$ average profiles for the GEOSCCM (black dashed) and 2D model (black solid). The top panel includes the trend derived from radiosonde data (RATPAC-A, pink asterisks) (Free et al., 2005).

age of air in the model is computed from a "clock" tracer that has a surface boundary condition linearly increasing with time, with no other chemical production or loss. This is essentially identical to the age obtained from simulations of $\mathrm{SF}_{6}$ or $\mathrm{CO}_{2}$ as done, for example, in Hall et al. (1999). The model slightly underestimates the observed age at $20 \mathrm{~km}$ at $\sim 30^{\circ}-40^{\circ}$ in both hemispheres, and at high latitudes of the $\mathrm{NH}$ above $30 \mathrm{~km}$. However for the most part, the model simulates the absolute values and the latitudinal and vertical gradients of the observations fairly well. This illustrates that the model transport rates in the stratosphere, i.e., the relative magnitudes of vertical motion and horizontal mixing, are generally realistic.

\section{B3 $\mathrm{N}_{2} \mathrm{O}$ and $\mathrm{H}_{2} \mathrm{O}$}

As further evaluation of the model transport, we show latitude-height cross sections of September $\mathrm{N}_{2} \mathrm{O}$ from the model and the AURA/Microwave Limb Sounder (MLS) data averaged over 2004-2009 (Fig. B5), and March $\mathrm{H}_{2} \mathrm{O}$ from the model and data from the UARS/Halogen Occultation Experiment (HALOE), both averaged over 1994-2004 (Fig. B6). Figure B6 includes data from AURA/MLS in 

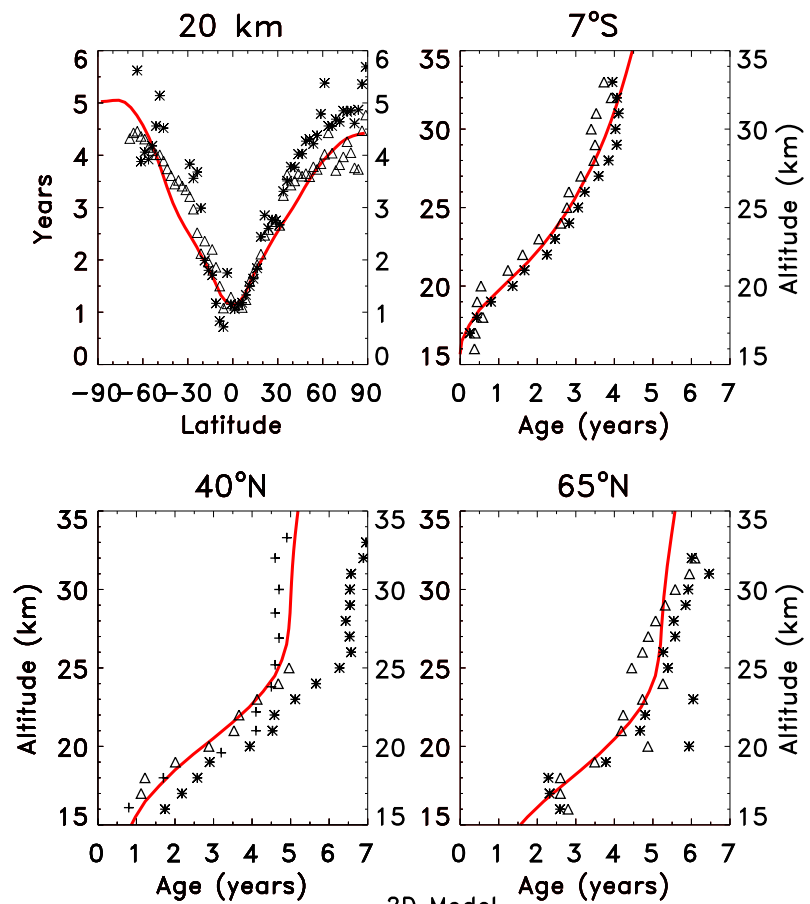

$\triangle \triangle E R-2$, OMS $\mathrm{CO}_{2}$

* $*$ ER-2, OMS SF 6

++ CWAS SF $_{6}$

Fig. B4. Age of air at $20 \mathrm{~km}$ derived from ER-2 aircraft measurements of $\mathrm{SF}_{6}$ (asterisks) and $\mathrm{CO}_{2}$ (triangles), and vertical profiles of the age of air derived from balloon measurements of $\mathrm{SF}_{6}$ (asterisks, plus signs) and $\mathrm{CO}_{2}$ (triangles) at the latitudes indicated. Ages derived from these measurements have been adapted from Hall et al. (1999). Also shown are simulations from the 2-D model averaged over the 1990s (red line). The age is taken relative to the tropical tropopause.

the polar regions (averaged over 2004-2009) where HALOE lacks data coverage. The model shows good overall agreement with the data in reproducing transport sensitive features in the meridional plane, including the horizontal and vertical gradients. For example, the model qualitatively simulates the region of strong horizontal mixing during late winter/early spring at midlatitudes of both hemispheres. This is especially pronounced in the SH during September at $20-40 \mathrm{~km}$ in the $\mathrm{N}_{2} \mathrm{O}$ field. The model tends to underestimate this mixing in the SH mid-upper stratosphere, as is also seen in the midlatitude vertical profile in Fig. B7 (top). Here the model compares well with the MLS $\mathrm{N}_{2} \mathrm{O}$ below $\sim 27 \mathrm{~km}$, but underestimates the data above this level, which is due to weaker than observed mixing of high- $\mathrm{N}_{2} \mathrm{O}$ air from lower latitudes.

In the Antarctic lower stratosphere, the observed $\mathrm{N}_{2} \mathrm{O}$ profile in September (Fig. B7, bottom) is mainly a result of descent within the vortex occurring throughout the winter, with little influence of air in-mixing from midlatitudes (SPARC CCMVal, 2010). The good model-data agreement here illustrates that the magnitudes of vortex descent and isolation from midlatitudes in the simulation are generally realistic.

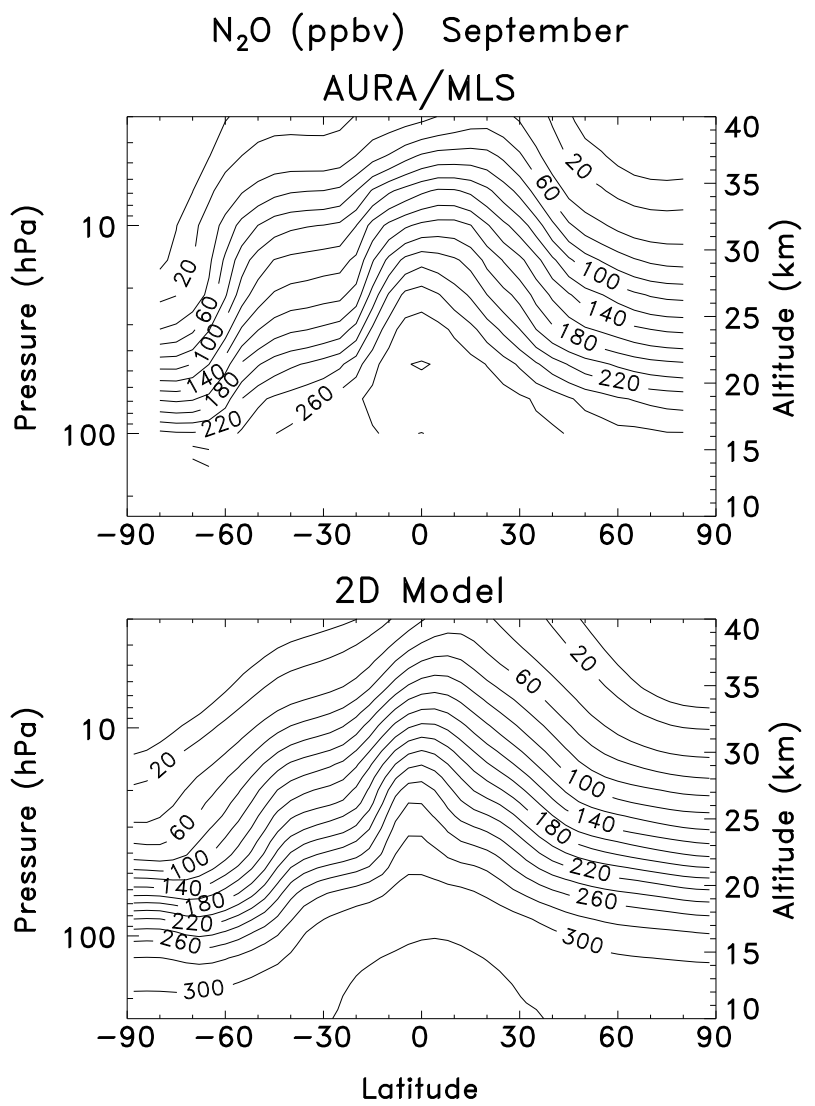

Fig. B5. Latitude-height cross-sections of September $\mathrm{N}_{2} \mathrm{O}$ averaged over 2004-2009 from AURA/MLS (top) and the 2-D model (bottom). Contour interval is $20 \mathrm{ppbv}$ and includes the $10 \mathrm{ppbv}$ contour.

The HALOE $\mathrm{H}_{2} \mathrm{O}$ data in Fig. B6 indicate strong poleward and downward transport of very dry air from the tropics to midlatitudes just above the tropopause (e.g., Randel et al., 2001). The model $\mathrm{H}_{2} \mathrm{O}$ is set to the HALOE climatology in the upper troposphere, below the red dashed line in Fig. B6. Above this level, the $\mathrm{H}_{2} \mathrm{O}$ field is computed in the model, and reveals that the model transport is resolving fairly well this strong poleward and downward transport from the tropical tropopause region.

In Figs. B5 and B6, the model also resolves the isolation of the tropics in the lower stratosphere, as indicated by strong horizontal gradients in the subtropics, and a region of low water vapor concentrations at $20-30 \mathrm{~km}$ over the equator associated with the "tape recorder" signal (e.g., Mote et al., 1996). This feature reflects the slow upward propagation of the water vapor seasonal cycle from the tropical tropopause, and simulation of this feature provides a good diagnostic of model transport. 

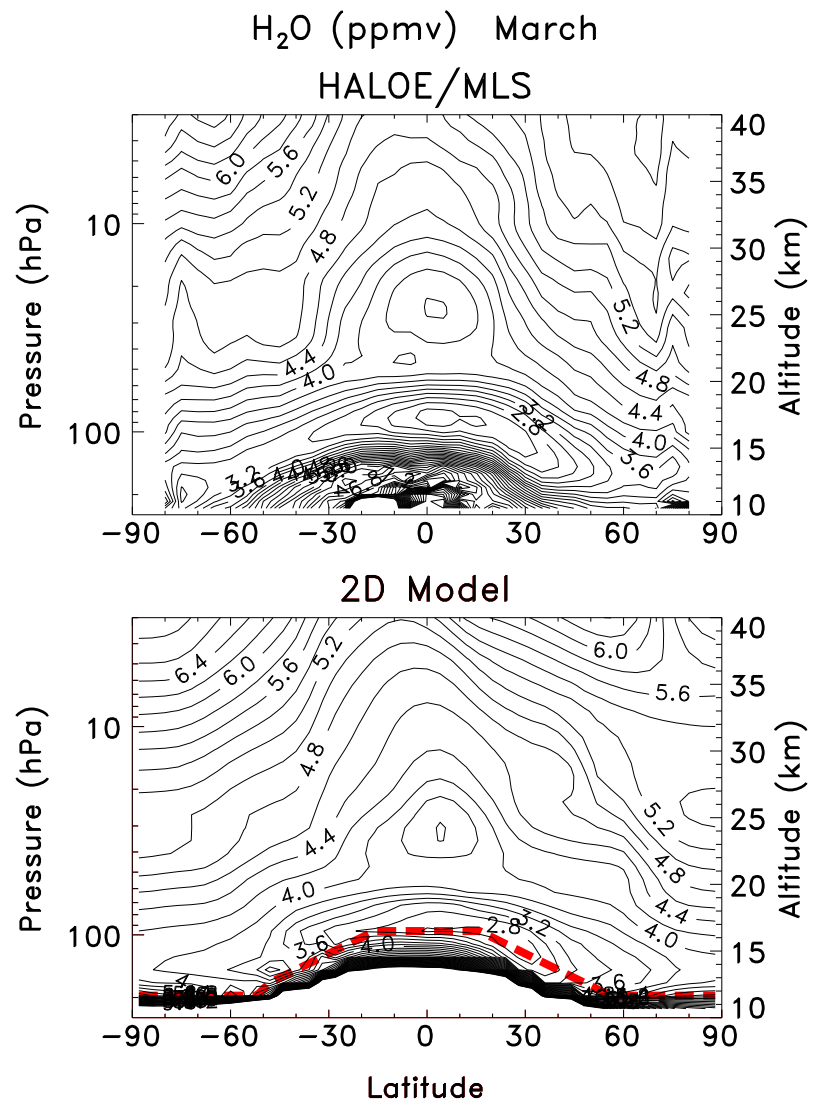

Fig. B6. Latitude-height cross-sections of March $\mathrm{H}_{2} \mathrm{O}$ averaged over 1994-2004 from UARS/HALOE (top) and the 2-D model (bottom). The top panel includes data from AURA/MLS in the polar regions (averaged over 2004-2009) where HALOE lacks data coverage. Contour interval is $0.2 \mathrm{ppmv}$. The red dashed line separates the regions where the model $\mathrm{H}_{2} \mathrm{O}$ is computed (above) and prescribed to the HALOE climatology (below).

Figure B8 shows the amplitude variation and phase lag versus altitude of the seasonal cycle in $\mathrm{H}_{2} \mathrm{O}+2 \mathrm{CH}_{4}$ at the equator relative to the tropopause from HALOE data (black asterisks). This quantity is quasi-conserved and accounts for both the $\mathrm{H}_{2} \mathrm{O}$ seasonal cycle propagation and the slow photochemical conversion of $\mathrm{CH}_{4}$ into $\mathrm{H}_{2} \mathrm{O}$ in the stratosphere. The amplitude attenuation and phase lag with increasing height reflect the strength in the upwelling of the BrewerDobson circulation (BDC) combined with the rate of vertical diffusion and entrainment of air from mid-latitudes (Hall et al., 1999). The model (red line) shows an increasingly longer phase lag compared with the data above $\sim 27 \mathrm{~km}$, possibly reflecting weaker BDC upwelling in the tropical middle stratosphere than indicated in the observations. However overall, the model shows mostly good agreement with the HALOE data in simulating this seasonal cycle propagation. This, combined with the good agreement in the tropical age profile (Fig. B4), suggests that the model transport rates in the tropical lower-middle stratosphere appear to be fairly realistic.
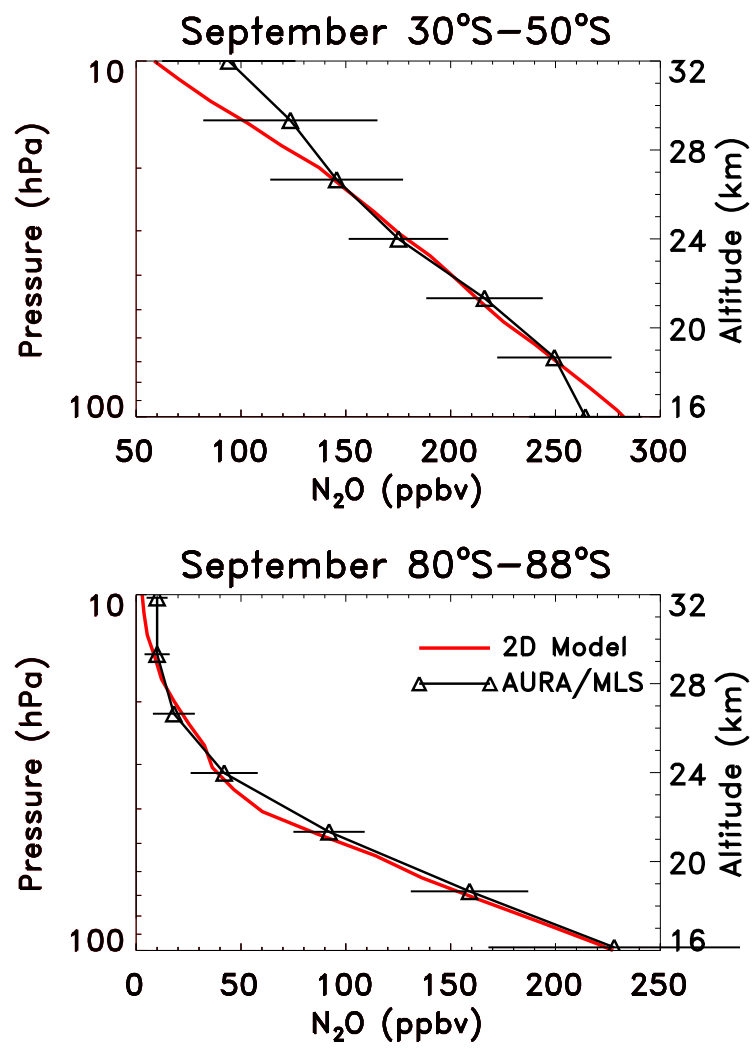

Fig. B7. Vertical profiles of September $\mathrm{N}_{2} \mathrm{O}$ at $30^{\circ} \mathrm{S}-50^{\circ} \mathrm{S}$ (top) and $80^{\circ} \mathrm{S}-88^{\circ} \mathrm{S}$ (bottom) from AURA/MLS observations (black triangles) and the 2-D model (red curve) averaged over 2004-2009. The error bars $(1 \sigma)$ denote the combined effects of measurement uncertainty and interannual variability. The Antarctic MLS profile is adapted from SPARC CCMVal (2010).

$\mathrm{H}_{2} \mathrm{O}+2 \mathrm{CH}_{4}$ seasonal cycle Equator

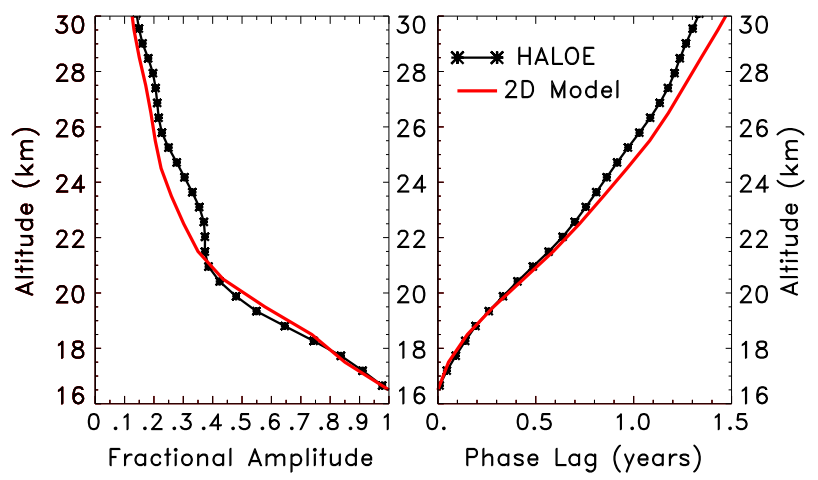

Fig. B8. Equatorial profiles of the amplitude and phase lag of the seasonal cyle in the quantity $\mathrm{H}_{2} \mathrm{O}+2 \mathrm{CH}_{4}$ from UARS/HALOE (black asterisks) and the 2-D model (red curve). Amplitudes are relative to the values at $16.5 \mathrm{~km}$, and the phase lag is defined to be zero at $16.5 \mathrm{~km}$. Values are averaged over 1994-2004 for both the data and model. 

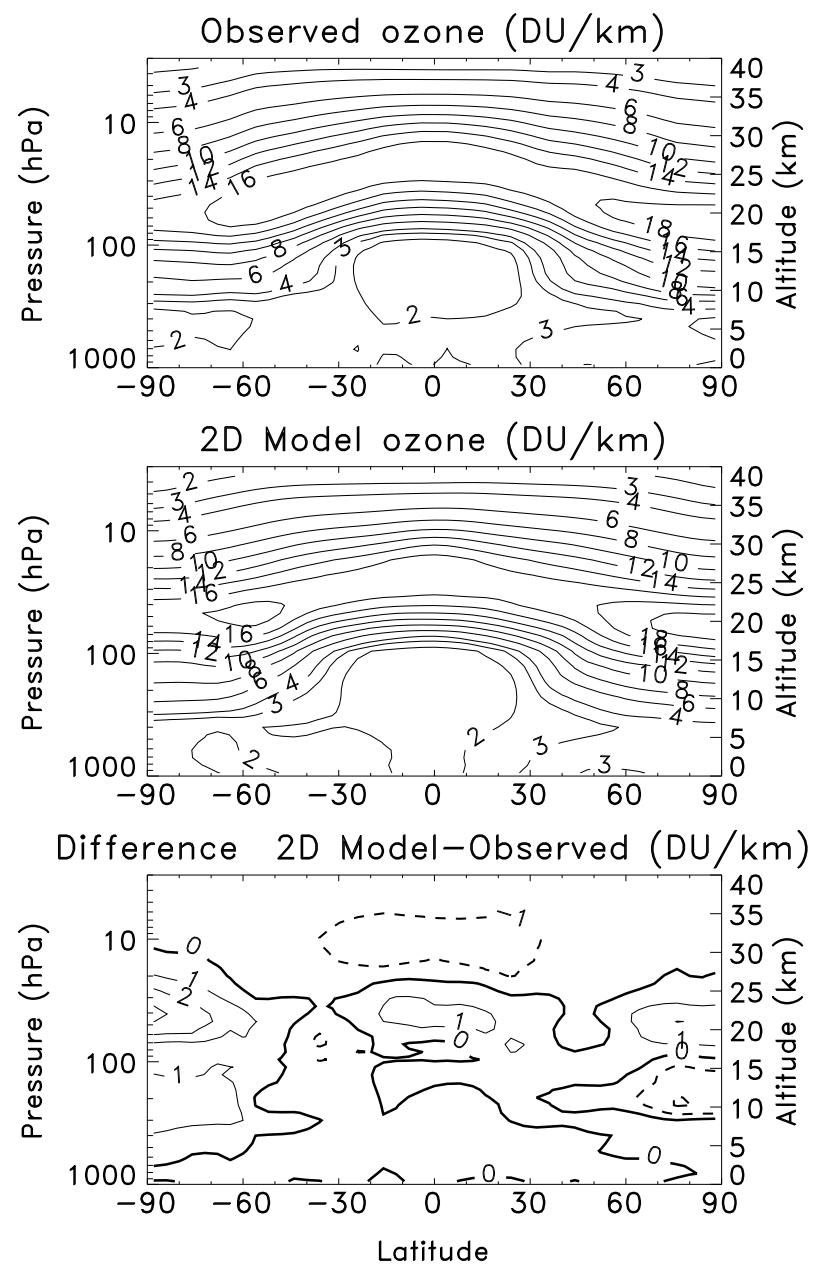

Fig. B9. Latitude-height cross-sections of annually averaged ozone expressed in Dobson Units per kilometer. The observations (top panel) are from the climatology compiled by McPeters et al. (2007) covering the time period 1988-2002. Also shown are the 2-D model simulation averaged over 1988-2002 (middle panel), and the difference, model minus observations (bottom panel). For the top and middle panels, the contour interval is $2 \mathrm{DU} \mathrm{km}^{-1}$ and includes the 3 contour level. For the bottom panel, the contour interval is $\pm 1 \mathrm{DU} \mathrm{km}^{-1}$, and dashed contours indicate negative differences.

\section{B4 Ozone}

Figure B9 shows latitude-height cross sections of annually averaged ozone from an observational climatology (top panel), the model (middle panel), and the difference, model minus data (bottom panel) expressed in DU per kilometer. This unit is proportional to the number density per $\mathrm{cm}^{2} \mathrm{di}-$ vided by a constant, and is a direct measure of the contribution versus altitude to the total column. The climatology is based on a combination of ground based and satellite data covering the time period 1988-2002, as compiled by McPeters et al. (2007). The model results are also averaged over 1988-2002.

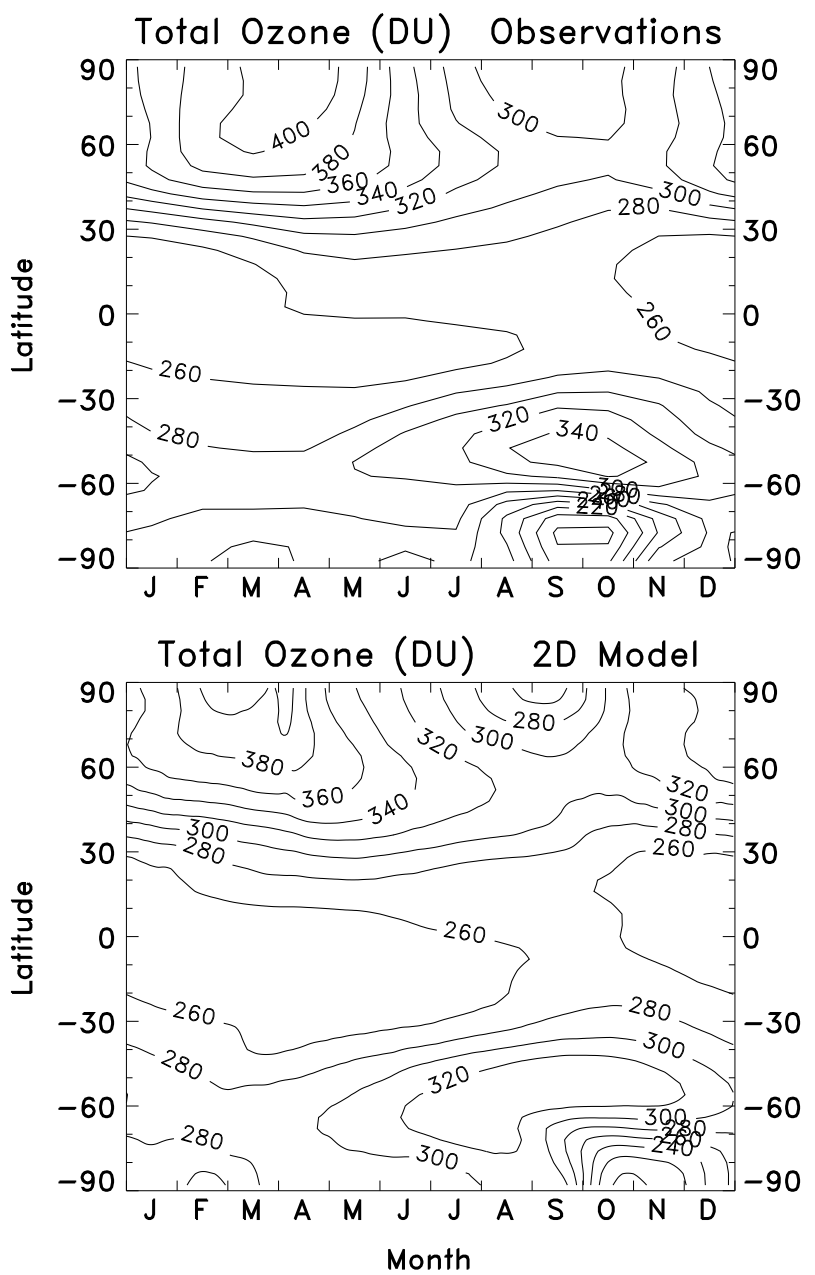

Fig. B10. Month-latitude cross-sections of total column ozone averaged over 1988-2002 from ground-based observations (top panel, updated from Fioletov et al., 2002) and 2-D model simulation (bottom panel). The contour interval is $20 \mathrm{DU}$.

The simulation compares relatively well with the data in most regards. The model qualitatively reproduces the observed latitudinal and vertical gradients in most places, as well as the magnitude of the ozone amounts. There are some regions of small discrepancy; for example in the polar regions at $20-25 \mathrm{~km}$ where the model overestimates ozone, especially in the $\mathrm{SH}$, and in the tropics above $30 \mathrm{~km}$ associated with the ozone deficit region where the model underestimates ozone (e.g., Jackman et al., 1996). The model also slightly underestimates the data at high $\mathrm{NH}$ latitudes near $10-15 \mathrm{~km}$ which is likely due to excessive horizontal mixing in this region, i.e., in-mixing of low-ozone air from the low-mid latitude troposphere. However, these model-measurement differences are now significantly smaller compared with previous model versions. 
The corresponding season-latitude sections of total column ozone also averaged over 1988-2002 are shown in Fig. B10. The observations are from ground-based measurements updated from Fioletov et al. (2002). Again the model shows good overall agreement with the data in reproducing the absolute total ozone amounts, the latitudinal gradients, and the seasonal variations. The main discrepancies occur at SH high latitudes where the onset of late winter/early spring ozone loss in the model is delayed by $\sim 1$ month, as is the seasonal filling of the ozone hole in late spring/early summer.

Acknowledgements. We thank Susan Strahan and Steve Steenrod for providing the GMI $\mathrm{CH}_{4}$ simulations; Vitali Fioletov for supplying the ground-based total ozone data; and Stacey Frith for providing the near global BUV/SBUV data and derived trends. This work was supported by the NASA Atmospheric Composition: Modeling and Analysis (ACMA) Program.

Edited by: W. Lahoz

\section{References}

Anderson Jr., D. E. and Lloyd, S. A.: Polar twilight UV-visible radiation field: perturbations due to multiple scattering, ozone depletion, stratospheric clouds, and surface albedo, J. Geophys. Res., 95, 7429-7434, 1990.

Austin, J. and Li, F.: On the relationship between the strength of the Brewer-Dobson circulation and the age of stratospheric air, Geophys. Res. Lett., 33, L17807, doi:10.1029/2006GL026867, 2006.

Austin, J., Wilson, J., Li, F., and Vomel, H.: Evolution of water vapor, and age of air in coupled chemistry-climate model simulations of the stratosphere, J. Atmos. Sci., 64(3), 905-921, 2007.

Austin, J., Scinocca, J., Plummer, D., Oman, L., Waugh, D., Akiyoshi, H., Bekki, S., Braesicke, P., Butchart, N., Chipperfield, M., Cugnet, D., Dameris, M., Dhomse, S., Eyring, V., Frith, S., Garcia, R. R., Garny, H., Gettelman, A., Hardiman, S. C., Kinnison, D., Lamarque, J. F., Mancini, E., Marchand, M., Michou, M., Morgenstern, O., Nakamura, T., Pawson, S., Pitari, G., Pyle, J., Rozanov, E., Shepherd, T. G., Shibata, K., Stolarski, R., Teyssedre, H., Wilson, R. J., and Yamashita, Y.: The decline and recovery of total column ozone using a multimodel time series analysis, J. Geophys. Res., 115, D00M10, doi:10.1029/2010JD013857, 2010.

Bacmeister, J. T., Schoeberl, M. R., Summers, M. E., Rosenfield, J. R., and Zhu, X.: Descent of long-lived trace gases in the winter polar vortex, J. Geophys. Res., 100, 11669-11684, 1995.

Brasseur, G. and Solomon, S.: Aeronomy of the Middle Atmosphere, 2nd Edn., D. Reidel, Dordrecht, Holland, 452 pp., 1986.

Butchart, N. and Scaife, A. A.: Removal of chlorofluorocarbons by increased mass exchange between the stratosphere and the troposphere in a changing climate, Nature, 410(6830), 799-802, 2001.

Butchart, N., Scaife, A. A., Bourqui, M., de Grandpre, J., Hare, S. H. E., Kettleborough, J., Langematz, U., Manzini, E., Sassi, F., Shibata, K., Shindell, D., and Sigmond, M.: Simulations of anthropogenic change in the strength of the Brewer-Dobson cir- culation, Clim. Dynam., 27, 727-741, doi:10.1007/s00382-0060162-4, 2006.

Butler, J. H., Battle, M., Bender, M. L., Montzka, S. A., Clarke, A. D., Saltzmank, E. S., Sucher, C. M., Severinghaus, J. P., and Elkins, J. W.: A record of atmospheric halocarbons during the twentieth century from polar firn air, Nature, 399, 749-755, 1999.

Chipperfield, M. P. and Feng, W.: Comment on: stratospheric ozone depletion at northern mid latitudes in the 21 st century: the importance of future concentrations of greenhouse gases nitrous oxide and methane, Geophys. Res. Lett., 30(7), 1389, doi:10.1029/2002GL016353, 2003.

Chou, M.-D. and Suarez, M. J.: A solar radiation parameterization for atmospheric studies, NASA Tech. Memo. NASA/TM-1999104606, 15, 40 pp., Greenbelt, Maryland, USA, 1999.

Chou, M.-D., Suarez, M. J., Liang, X.-Z., and Yan, M.-H.: A thermal infrared radiation parameterization for atmospheric studies, NASA Tech. Memo. NASA/TM-2001-104606, 9, 56 pp., Greenbelt, Maryland, USA, 2001.

Considine, D. B., Douglass, A. R., and Jackman, C. H.: Effects of a polar stratospheric cloud parameterization on ozone depletion due to stratospheric aircraft in a two-dimensional model, J. Geophys. Res., 99, 18879-18894, 1994.

Crutzen, P.: Upper limits on atmospheric ozone reductions following increased application of fixed nitrogen to the soil, Geophys. Res. Lett., 3, 169-172, 1976.

Daniel, J. S., Fleming, E. L., Portmann, R. W., Velders, G. J. M., Jackman, C. H., and Ravishankara, A. R.: Options to accelerate ozone recovery: ozone and climate benefits, Atmos. Chem. Phys., 10, 7697-7707, doi:10.5194/acp-10-7697-2010, 2010.

Douglass, A. R., Stolarski, R. S., Schoeberl, M. R., Jackman, C. H., Gupta, M. L., Newman, P. A., Nielsen, J. E., and Fleming, E. L.: Relationship of loss, mean age of air and the distribution of CFCs to stratospheric circulation and implications for atmospheric lifetimes, J. Geophys. Res., 113, D14309, doi:10.1029/2007JD009575, 2008.

Duncan, B. N., Strahan, S. E., Yoshida, Y., Steenrod, S. D., and Livesey, N.: Model study of the cross-tropopause transport of biomass burning pollution, Atmos. Chem. Phys., 7, 3713-3736, doi:10.5194/acp-7-3713-2007, 2007.

Engel, A., Mobius, T., Bonisch, H., Schmidt, U., Heinz, R., Levin, I., Atlas, E., Aoki, S., Nakazawa, T., Sugawara, S., Moore, F., Hurst, D., Elkins, J., Schauffler, S., Andrews, A., and Boering, K.: Age of stratospheric air unchanged within uncertainties over the past 30 years, Nat. Geosci., 2, 28-31, 2009.

Eyring, V., Butchart, N., Waugh, D. W., Akiyoshi, H., Austin, J., Bekki, S., Bodeker, G. E., Boville, B. A., Bruhl, C., Chipperfield, M. P., Cordero, E., Dameris, M., Deushi, M., Fioletov, V. E., Frith, S. M., Garcia, R. R., Gettelman, A., Giorgetta, M. A., Grewe, V., Jourdain, L., Kinnison, D. E., Mancini, E., Manzini, E., Marchand, M., Marsh, D. R., Nagashima, T., Newman, P. A., Nielsen, J. E., Pawson, S., Pitari, G., Plummer, D. A., Rozanov, E., Schraner, M., Shepherd, T. G., Shibata, K., Stolarski, R. S., Struthers, H., Tian, W., and Yoshiki, M.: Assessment of temperature, trace species, and ozone in chemistry-climate model simulations of the recent past, J. Geophys. Res., 111, D22308, doi:10.1029/2006JD007327, 2006.

Eyring, V., Waugh, D. W., Bodeker, G. E., Cordero, E., Akiyoshi, H., Austin, J., Beagley, S. R., Boville, B., Braesicke, P., Bruhl, 
C., Butchart, N., Chipperfield, M. P., Dameris, M., Deckert, R., Deushi, M., Frith, S. M., Garcia, R. R., Gettelman, A., Giorgetta, M., Kinnison, D. E., Mancini, E., Manzini, E., Marsh, D. R., Matthes, S., Nagashima T., Newman, P. A., Nielsen, J. E., Pawson, S., Pitari, G., Plummer, D. A., Rozanov, E., Schraner, M., Scinocca, J. F., Semeniuk K., Shepherd, T. G., Shibata, K., Steil, B., Stolarski, R., Tian, W., and Yoshiki, M.: Multimodel projections of stratospheric ozone in the 21 st century, J. Geophys. Res., 112, D16303, doi:10.1029/2006JD008332, 2007.

Eyring, V., Cionni, I., Lamarque, J. F., Akiyoshi, H., Bodeker, G. E., Charlton-Perez, A. J., Frith, S. M., Gettelman, A., Kinnison, D. E., Nakamura, T., Oman, L. D., Pawson, S., and Yamashita, Y.: Sensitivity of 21st century stratospheric ozone to greenhouse gas scenarios, Geophys. Res. Lett., 37, L16807, doi:10.1029/2010GL044443, 2010a.

Eyring, V., Cionni, I., Bodeker, G. E., Charlton-Perez, A. J., Kinnison, D. E., Scinocca, J. F., Waugh, D. W., Akiyoshi, H., Bekki, S., Chipperfield, M. P., Dameris, M., Dhomse, S., Frith, S. M., Garny, H., Gettelman, A., Kubin, A., Langematz, U., Mancini, E., Marchand, M., Nakamura, T., Oman, L. D., Pawson, S., Pitari, G., Plummer, D. A., Rozanov, E., Shepherd, T. G., Shibata, K., Tian, W., Braesicke, P., Hardiman, S. C., Lamarque, J. F., Morgenstern, O., Pyle, J. A., Smale, D., and Yamashita, Y.: Multi-model assessment of stratospheric ozone return dates and ozone recovery in CCMVal-2 models, Atmos. Chem. Phys., 10, 9451-9472, doi:10.5194/acp-10-9451-2010, 2010b.

Fioletov, V. E., Bodeker, G. E., Miller, A. J., McPeters, R. D., and Stolarski, R.: Global ozone and zonal total ozone variations estimated from ground-based and satellite measurements: 1964-2000, J. Geophys. Res., 107(D22), 4647, doi:10.1029/2001JD001350, 2002.

Fisher, D. A., Hales, C. H., Filkin, D. L., Ko, M. K. W., Sze, N. D., Connell, P. S., Wuebbles, D. J., Isaksen, I. S. A., and Stordal, F.: Model calculations of the relative effects of CFCs and their replacements on stratospheric ozone, Nature, 344(6266), 508-512, 1990.

Fleming, E. L., Jackman, C. H., Weisenstein, D. K., and Ko, M. K. W.: The impact of inter-annual variability on multidecadal total ozone simulations, J. Geophys. Res., 112, D10310, doi:10.1029/2006JD007953, 2007.

Free, M., Seidel, D. J., Angell, J. K., Lanzante, J., Durre, I., and Peterson, T. C.: Radiosonde atmospheric temperature products for assessing climate (RATPAC): a new data set of largearea anomaly time series, J. Geophys. Res., 110, D22101, doi:10.1029/2005JD006169, 2005.

Garcia, R. R.: Parameterization of planetary wave breaking in the middle atmosphere, J. Atmos. Sci., 48(11), 1405-1419, 1991.

Garcia, R. R. and Randel, W. J.: Acceleration of the Brewer-Dobson circulation due to increases in greenhous gases, J. Atmos. Sci., 65, 2731-2739, 2008.

Garcia, R. R., Marsh, D. R., Kinnison, D. E., Boville, B. A., and Sassi, F.: Simulation of secular trends in the middle atmosphere, 1950-2003, J. Geophys. Res., 112, D09301, doi:10.1029/2006JD007485, 2007.

Haigh, J. D. and Pyle, J. A.: A two-dimensional calculation including atmospheric carbon dioxide and stratospheric ozone, Nature, 279, 222-224, 1979.

Hall, T. M. and Waugh, D. W.: Influence of nonlocal chemistry on tracer distributions: inferring the mean age of air from $\mathrm{SF}_{6}, \mathrm{~J}$.
Geophys. Res., 103, 13327-13336, 1998.

Hall, T. M., Waugh, D. W., Boering, K. A., and Plumb, R. A.: Evaluation of transport in stratospheric models, J. Geophys. Res., 104, 18815-18839, 1999.

Hansen, J. and Sato, M.: Greenhouse gas growth rates, P. Natl. Acad. Sci. USA, 101(46), 16109-16114, 2004.

Herman, J. R. and Celarier, E. A.: Earth surface reflectivity climatology at 340-380 nm from TOMS data, J. Geophys. Res., 102(D23), 28003-28011, 1997.

IPCC (Intergovernmental Panel on Climate Change): Special report on emissions scenarios: a special report of Working Group III of the Intergovernmental Panel on Climate Change, 599 pp., Cambridge University Press, Cambridge, UK, 2000.

IPCC (Intergovernmental Panel on Climate Change): Climate Change 2007: The Physical Science Basis. Contribution of Working Group I to the Fourth Assessment Report of the Intergovernmental Panel on Climate Change, edited by: Solomon, S., Qin, D., Manning, M., Chen, Z., Marquis, M., Averyt, K. B., Tignor, M., Miller, H. L., Cambridge University Press, New York, 996 pp., 2007.

Jackman, C. H., Fleming, E. L., Chandra, S., Considine, D. B., and Rosenfield, J. E.: Past, present, and future modeled ozone trends with comparisons to observed trends, J. Geophys. Res., 101, 28753-28767, 1996.

Kaye, J. A., Penkett, S. A., and Ormond, F. M.: Report on concentrations, lifetimes, and trends of CFCs, halons, and related species, NASA Reference Publication 1339, 247 pp., Washington, D.C., USA, 1994.

Kistler, R., Kalnay, E., Collins, W., Suranjana, S., White, G., Woollen, J., Chelliah, M., Ebisuzaki, W., Kanamitsu, M., Kousky, V., van den Dool, H., Jenne, R., and Fiorino, M.: The NCEP-NCAR 50-year reanalysis: monthly means CD-ROM and documentation, B. Am. Meteorol. Soc., 82, 247-267, 2001.

Kodama, C., Iwasaki, T., Shibata, K., and Yukimoto, S.: Changes in the stratospheric mean meridional circulation due to increased $\mathrm{CO}_{2}$ : radiation- and sea surface temperature-induced effects, J. Geophys. Res., 112, D16103, doi:10.1029/2006JD008219, 2007.

Li, F., Austin, J., and Wilson, J.: The strength of the Brewer-Dobson circulation in a changing climate: coupled chemistry-climate model simulations, J. Climate, 21, 40-57, 2008.

Li, F., Stolarski, R. S., and Newman, P. A.: Stratospheric ozone in the post-CFC era, Atmos. Chem. Phys., 9, 2207-2213, doi:10.5194/acp-9-2207-2009, 2009.

McPeters, R. D., Labow, G. J., and Logan, J. A.: Ozone climatological profiles for satellite retrieval algorithms, J. Geophys. Res., 112, D05308, doi:10.1029/2005JD006823, 2007.

Newchurch, M. J., Yang, E.-S., Cunnold, D. M., Reinsel, G. C., Zawodny, J. M., and Russell III, J. M.: Evidence for slowdown in stratospheric ozone loss: first stage of ozone recovery, J. Geophys. Res., 108(D16), 4507, doi:10.1029/2003JD003471, 2003.

Newman, P. A., Schoeberl, M. R., Plumb, R. A., and Rosenfield, J. E.: Mixing rates calculated from potential vorticity, J. Geophys. Res., 93, 5221-5240, 1988.

Newman, P. A., Oman, L. D., Douglass, A. R., Fleming, E. L., Frith, S. M., Hurwitz, M. M., Kawa, S. R., Jackman, C. H., Krotkov, N. A., Nash, E. R., Nielsen, J. E., Pawson, S., Stolarski, R. S., and Velders, G. J. M.: What would have happened to the ozone layer if chlorofluorocarbons (CFCs) had not been regulated?, Atmos. Chem. Phys., 9, 2113-2128, doi:10.5194/acp-9- 
2113-2009, 2009.

Olsen, M. A., Schoeberl, M. R., and Nielsen, J. E.: Response of stratospheric circulation and stratosphere-troposphere exchange to changing sea surface temperatures, J. Geophys. Res., 112, D16104, doi:10.1029/2006JD008012, 2007.

Oman, L., Waugh, D. W., Pawson, S., Stolarski, R. S., and Newman, P. A.: On the influence of anthropogenic forcings on changes in the stratospheric mean age, J. Geophys. Res., 114, D03105, doi:10.1029/2008JD010378, 2009.

Park, J. H., Ko, M. K. W., Jackman, C. H., Plumb, R. A., Kaye, J. A., and Sage, K. H. (Eds.): Models and Measurements Intercomparison II, NASA Tech. Memo., TM-1999-209554, Hampton, VA, USA, 1999.

Pawson, S., Stolarski, R. S., Douglass, A. R., Newman, P. A., Nielsen, J. E., Frith, S. M., and Gupta, M. L.: Goddard earth observing system chemistry-climate model simulations of stratospheric ozone-temperature coupling between 1950 and 2005, J. Geophys. Res., 113, D12103, doi:10.1029/2007JD009511, 2008.

Plumb, R. A. and Mahlman, J. D.: The zonally averaged transport characteristics of the GFDL general circulation/transport model, J. Atmos. Sci., 44, 298-327, 1987.

Portmann, R. W. and Solomon, S.: Indirect radiative forcing of the ozone layer during the 21 st century, Geophys. Res. Lett., 34, L02813, doi:10.1029/2006GL028252, 2007.

Ramaswamy, V., Boucher, O., Haigh, J., Hauglustaine, D., Haywood, J., Myhre, G., Nakajima, T., Shi, G. Y., and Solomon, S.: Radiative Forcing of Climate Change, in: Climate Change 2001: The Scientific Basis, Contribution of Working Group I to the Third Assessment Report of the Intergovernmental Panel on Climate Change (IPCC), edited by: Houghton, J. T., Ding, Y., Griggs, D. J., Noguer, M., van der Linden, P. J., Dai, X., Maskell, K., and Johnson, C. A., Cambridge University Press, Cambridge, United Kingdom and New York, NY, USA, p. 881, 2001a.

Ramaswamy, V., Chanin, M.-L., Angell, J., Barnett, J., Gaffen, D., Gelman, M., Keckhut, P., Koshelkov, Y., Labitzke, K., Lin, J.J.R., O’Neill, A., Nash, J., Randel, W., Rood, R., Shine, K., Shiotani, M., and Swinbank, R.: Stratospheric temperature trends: observations and model simulations, Rev. Geophys., 39(1), 71122, $2001 b$.

Randel, W. J., Wu, F., Gettelman, A., Russell III, J. M., Zawodny, J. M., and Oltmans, S. J.: Seasonal variation of water vapor in the lower stratosphere observed in halogen occultation experiment data, J. Geophys. Res., 106, 14313-14325, 2001.

Randeniya, L. K., Vohralik, P. F., and Plumb, I. C.: Stratospheric ozone depletion at northern mid latitudes in the 21 st century: the importance of future concentrations of greenhouse gases nitrous oxide and methane, Geophys. Res. Lett., 29(4), 1051, doi:10.1029/2001GL014295, 2002.

Ravishankara, A. R., Daniel, J. S., and Portmann, R. W.: Nitrous oxide $\left(\mathrm{N}_{2} \mathrm{O}\right)$ : the dominant ozone-depleting substance emitted in the 21st century, Science, 326, 123-125, 2009.

Ray, E. A., Moore, F. L., Elkins, J. W., Dutton, G. S., Fahey, D. W., Vomel, H., Oltmans, S. J., and Rosenlof, K. H.: Transport into the Northern Hemisphere lowermost stratosphere revealed by in situ tracer measurements, J. Geophys. Res., 104, 26565-26580, 1999.

Reinsel, G. C.: Trend analysis of upper stratospheric Umkehr ozone data for evidence of turnaround, Geophys. Res. Lett., 29(10), 1451, doi:10.1029/2002GL014716, 2002.
Rontu Carlon, N., Papanastasiou, D. K., Fleming, E. L., Jackman, C. H., Newman, P. A., and Burkholder, J. B.: UV absorption cross sections of nitrous oxide $\left(\mathrm{N}_{2} \mathrm{O}\right)$ and carbon tetrachloride $\left(\mathrm{CCl}_{4}\right)$ between 210 and $350 \mathrm{~K}$ and the atmospheric implications, Atmos. Chem. Phys., 10, 6137-6149, doi:10.5194/acp10-6137-2010, 2010.

Rosenfield, J. E. and Douglass, A. R.: Doubled $\mathrm{CO}_{2}$ effects on $\mathrm{NO}_{\mathrm{y}}$ in a coupled 2-D model, Geophys. Res. Lett., 25(23), 43814384, 1998.

Rosenfield, J. E., Considine, D. B., Meade, P. E., Bacmeister, J. T., Jackman, C. H., and Schoeberl, M. R.: Stratospheric effects of Mount Pinatubo aerosol studied with a coupled two-dimensional model, J. Geophys. Res., 102, 3649-3670, 1997.

Rosenfield, J. E., Douglass, A. R., and Considine, D. B.: The impact of increasing carbon dioxide on ozone recovery, J. Geophys. Res., 107(D6), 4049, doi:10.1029/2001JD000824, 2002.

Sander, S. P., Friedl, R. R., Golden, D. M., Kurylo, M. J., Moortgat, G. K., Keller-Rudek, H., Wine, P. H., Ravishankara, A. R., Kolb, C. E., Molina, M. J., Finlayson-Pitts, B. J., Huie, R. E., and Orkin, V. L.: Chemical kinetics and photochemical data for use in atmospheric studies, Evaluation number 15, JPL Publ., 06-2, 2006.

Shepherd, T. G. and Jonsson, A. I.: On the attribution of stratospheric ozone and temperature changes to changes in ozonedepleting substances and well-mixed greenhouse gases, Atmos. Chem. Phys., 8, 1435-1444, doi:10.5194/acp-8-1435-2008, 2008.

Shine, K. P, Bourqui, M. S., de Forster, P. M., Hare, S. H. E., Langematz, U., Braesicke, P., Grewe, V., Ponater, M., Schnadt, C., Smith, C. A., Haigh, J. D., Austin, J., Butchart, N., Shindell, D. T., Randel, W. J., Nagashima, T., Portmann, R. W., Solomon, S., Seidel, D. J., Lanzante, J., Klein, S., Ramaswamy, V., and Schwarzkopf, M. D.: A comparison of model-simulated trends in stratospheric temperatures, Q. J. Roy. Meteorol. Soc., 129, 1565-1588, 2003.

Solomon, S., Tuck, A. F., Mills, M., Heidt, L. E., and Pollock, W. H.: On the evaluation of ozone depletion potentials, J. Geophys. Res., 97, 825-842, 1992.

SPARC CCMVal: SPARC Report on the Evaluation of ChemistryClimate Models, edited by: Eyring, V., Shepherd, T. G., and Waugh, D. W., SPARC Report No. 5, WCRP-132, WMO/TDNo. 1526, available at: http://www.atmosp.physics.utoronto.ca/ SPARC, 2010.

Stolarski, R. S., Douglass, A. R., Gupta, M., Newman, P. A., Pawson, S., Schoeberl, M. R., and Nielsen, J. E.: An ozone increase in the Antarctic summer stratosphere: a dynamical response to the ozone hole, Geophys. Res. Lett., 33, L21805, doi:10.1029/2006GL026820, 2006.

Stolarski, R. S., Douglass, A. R., Newman, P. A., Pawson, S., and Schoeberl, M. R.: Relative contribution of greenhouse gases and ozone-depleting substances to temperature trends in the stratosphere: a chemistry-climate model study, J. Climate, 23, 28-42, 2010.

Strahan, S. E., Duncan, B. N., and Hoor, P.: Observationally derived transport diagnostics for the lowermost stratosphere and their application to the GMI chemistry and transport model, Atmos. Chem. Phys., 7, 2435-2445, doi:10.5194/acp-7-2435-2007, 2007. 
Strobel, D. F.: Parameterization of the atmospheric heating rate from 15 to $120 \mathrm{~km}$ due to $\mathrm{O}_{2}$ and $\mathrm{O}_{3}$ absorption of solar radiation, J. Geophys. Res., 83(C12), 6225-6230, 1978.

Waugh, D. W., Oman, L., Kawa, S. R., Stolarski, R. S., Pawson, S., Douglass, A. R., Newman, P. A., and Nielsen, J. E.: Impacts of climate change on stratospheric ozone recovery, Geophys. Res. Lett., 36, L03805, doi:10.1029/2008GL036223, 2009.

World Meteorological Organization (WMO), Scientific Assessment of Ozone Depletion: 2002, Rep. 47 Global Ozone Research and Monitoring Project, Geneva, 2003.
World Meteorological Organization (WMO), Scientific Assessment of Ozone Depletion: 2006, Rep. 50 Global Ozone Research and Monitoring Project, Geneva, 2007.

World Meteorological Organization (WMO), Scientific Assessment of Ozone Depletion: 2010, Rep. 52 Global Ozone Research and Monitoring Project, Geneva, 2011.

Wuebbles, D. J.: Chlorocarbon emission scenarios: potential impact on stratospheric ozone, Geophys. Res. Lett., 88(C2), 14331443, 1983. 